\title{
CAMPO GRAVIMÉTRICO DO COMPLEXO ALCALINO DE TAPIRA (MG): COMPARAÇÃO ENTRE TÉCNICAS DE INTERPOLAÇÃO E DE SEPARAÇÃO REGIONAL-RESIDUAL
}

\author{
Vanessa Biondo Ribeiro e Marta Silvia Maria Mantovani \\ Recebido em 5 janeiro, 2010 / Aceito em 15 julho, 2011 \\ Received on January 5, 2010 / Accepted on July 15, 2011
}

\begin{abstract}
The Tapira Alkaline Complex is an intrusion in the southeast region of the Alto do Paranaíba Province, Minas Gerais State, Brazil. This study means to test numerical tools used in data reduction for obtaining the physical properties of the Tapira Alkaline complex using gravimetric ground survey data. The gravimetric ground survey was done over the area occupied by the complex, and also in its adjacents. By the analysis of the achieved data, a regional gravimetric field was estimated, looking for the isolation of the body's gravimetric contribution. For this purpose, four different interpolation methods were used: inverse distance, triangulation, kriging and minimum curvature. The separation of the gravimetric contribution, due to local or regional sources and residuals, was performed using three numerical methods: omission, upward continuation and robust polynomial fitting. In order to compare them a profile was defined over the isolated gravimetric anomaly, in each case. The comparison among different interpolation methods, so as the regional-residual separation, allowed establishing which methodology works better to the study's objective. The most effective interpolation to the presented case was the kriging method, while the best one to the regional-residual separation was the first degree robust polynomial fitting.
\end{abstract}

Keywords: alkaline complex, Tapira, gravimetry.

RESUMO. 0 Complexo Alcalino de Tapira é uma intrusão no extremo sul da Província do Alto da Paranaíba, MG. Este trabalho visa testar ferramentas utilizadas no tratamento dos dados, para estudar as propriedades físicas do Complexo Alcalino de Tapira utilizando gravimetria terrestre. 0 levantamento gravimétrico terrestre foi realizado não apenas sobre a área ocupada pelo complexo, como também nas adjacências. Através da análise dos dados obtidos nesse levantamento, foi estimado 0 campo gravimétrico regional, visando isolar a contribuição gravimétrica do corpo. Para este propósito, foram analisados quatro métodos de interpolação: inverso da distância, triangulação, kriging e mínima curvatura. A separação da contribuição gravimétrica, devida a fontes locais ou regionais e residuais, foi realizada utilizando três métodos numéricos: método da omissão, continuação para cima ( upward continuation) e ajuste polinomial robusto. Para compará-los, foi traçado um perfil sobre a anomalia gravimétrica isolada em cada caso. A comparação entre diferentes métodos de interpolação, assim como os de separação regional-residual, permitiu determinar qual metodologia melhor se aplica ao alvo do estudo. Verificou-se que o método de interpolação que melhor responde ao caso apresentado é 0 kriging, enquanto a separação regional-residual que apresenta melhor resultado é o ajuste polinomial robusto de grau 1.

Palavras-chave: complexo alcalino, Tapira, gravimetria. 


\section{INTRODUÇÃo}

Na porção meridional brasileira e correspondente africana (Namíbia e Angola), os complexos alcalinos se distribuem ao longo dos lineamentos tectônicos, tendo ocorrido após o grande evento toleítico que precedeu a deriva entre os dois continentes. Em geral, esses complexos são subcirculares a ovais, indicativos da ocorrência de uma grande energia que provocou ascensão de magma. Dados geoquímicos indicam que os carbonatitos se originam em processos de imiscibilidade a partir de magmas traquito-fonólitos (Comin-Chiaramonti et al., 2007). São, portanto, rochas ígneas que contêm mais de 50\% de carbonatos, o que the atribui uma composição mineralógica próxima dos calcários e mármores, utilizados como corretivo de acidez em solos tropicais (Melamed et al., 2007), e de grande importância na indústria brasileira de fertilizantes. Formam estruturas em anel, localizando-se na parte interna do complexo alcalino. Em quase sua totalidade estão restritos a áreas continentais. Corpos isolados como esses podem ser identificados em levantamentos geofísicos (gravimetria e magnetometria).

Dependendo de suas características físicas, sua geometria subsuperficial pode ser modelada após adequado tratamento dos dados levantados. Os complexos alcalinos brasileiros apresentam uma grande variedade petrográfica devido, em parte, a origens magmáticas distintas e a processos físico-químicos diferenciados. Essa diversidade está refletida numa grande variação de mineralogia das rochas, e por consequência, na densidade específica. Quando o contraste de densidade entre a alcalina e a rocha encaixante é significativo, o método gravimétrico se torna o mais adequado para o estudo de intrusões magmáticas, mesmo se comparado aos métodos sísmicos (Vigneresse, 1995).

0 método gravimétrico permite delimitar lateralmente a fonte da anomalia gravimétrica devido ao contraste de densidade entre a fonte causadora e a rocha encaixante. Através desse contraste é possível analisar a geometria em subsuperfície do objeto de estudo.

Com base nessas observações foi selecionado o Complexo Alcalino de Tapira para o presente estudo.

0 Complexo Alcalino de Tapira caracteriza-se por ser 0 componente mais meridional de uma série de intrusões contendo carbonatitos que ocorrem na Província do Alto Paranaíba, Minas Gerais. Para analisar a resposta gravimétrica deste complexo foi realizado um levantamento gravimétrico terrestre abrangendo a região da alcalina e áreas adjacentes. Através de correções rotineiras adequadas, aplicadas aos valores de gravidade medidos, calculou-se o valor da anomalia Bouguer completa na região para, posteriormente, isolar a contribuição gravimétrica do corpo.

Antes de qualquer interpretação ou modelagem dos dados gravimétricos, é necessário fazer uma análise do método de interpolação e de separação regional-residual para evitar 0 falseamento dos dados, ou mesmo a geração de pseudo-anomalias sem representatividade geológica.

Essa análise é o foco do presente trabalho, que tem por objetivo, inicialmente, comparar a resposta obtida pela utilização de diferentes métodos de interpolação aos dados gravimétricos obtidos, visando uma melhor representação da anomalia obtida. Para tal foram aplicados os métodos do inverso da distância, triangulação, "kriging" e mínima curvatura (Yang et al., 2004). Como segundo objetivo, foram analisados diferentes métodos de separação entre as componentes regional e residual do campo gravimétrico observado da região. Os métodos considerados ao longo do trabalho foram: método da omissão, continuação para cima (upward continuation) e ajuste polinomial robusto (Beltrão et al., 1991).

Um estudo gravimétrico completo permitiria modelar os corpos identificados em superfície com geometria 3D, devido ao alto contraste de densidades observada ente a rocha encaixante e os corpos intrusivos. Entretanto o objetivo do presente trabalho limita-se a uma etapa anterior àquela da modelagem.

\section{GEOLOGIA REGIONAL}

0 Complexo Alcalino de Tapira intrude nas rochas do Cinturão Móvel Brasília, de idade Neoproterozóica, adjacente ao Cráton do São Francisco. Segundo Silva et al. (2006), a Faixa Brasília na região de Tapira, exibe um conjunto de três escamas, com características litológicas distintas delimitadas por falhas de cavalgamento sobre 0 Grupo Bambuí (Fig. 1). A constituição litológica destes domínios é dividida em quatro grupos: Grupo Bambuí, Escama Inferior (Grupo Canastra), Escama intermediária (Grupo Canastra), Escama Superior (Grupo Araxá).

A chaminé de Tapira é caracterizada como uma estrutura semicircular encaixada em quartzitos, filitos e xistos pré-cambrianos do grupo Canastra (Tavares et al., 2008). Estas rochas constituem um anel completo em volta desse complexo, se apresentando totalmente fenitizadas na borda sudoeste (Fig. 1). Observa-se que o contato do corpo intrusivo com a rocha encaixante é preferencialmente vertical e irregular.

0 Complexo de Tapira é uma chaminé ultramáfica-alcalinacarbonatítica com cerca de $35 \mathrm{~km}^{2}$ de superfície, $7.4 \mathrm{~km}$ no eixo NE por 6.0 km na direção NW (Fig. 2). Segundo Brod et al. (2004), a ocorrência da intrusão está associada ao evento magmático relacionado à abertura do Oceano Atlântico, que afetou a Plataforma Brasileira entre o final do Jurássico e o Terciário Inferior e que teve início com os derrames basálticos da Bacia do Paraná.

A alcalina de Tapira é formada por diversas intrusões de rochas plutônicas silicáticas e, em menor quantidade, por carbonatitos. A série plutônica consiste, em sua maioria de bebedou- 


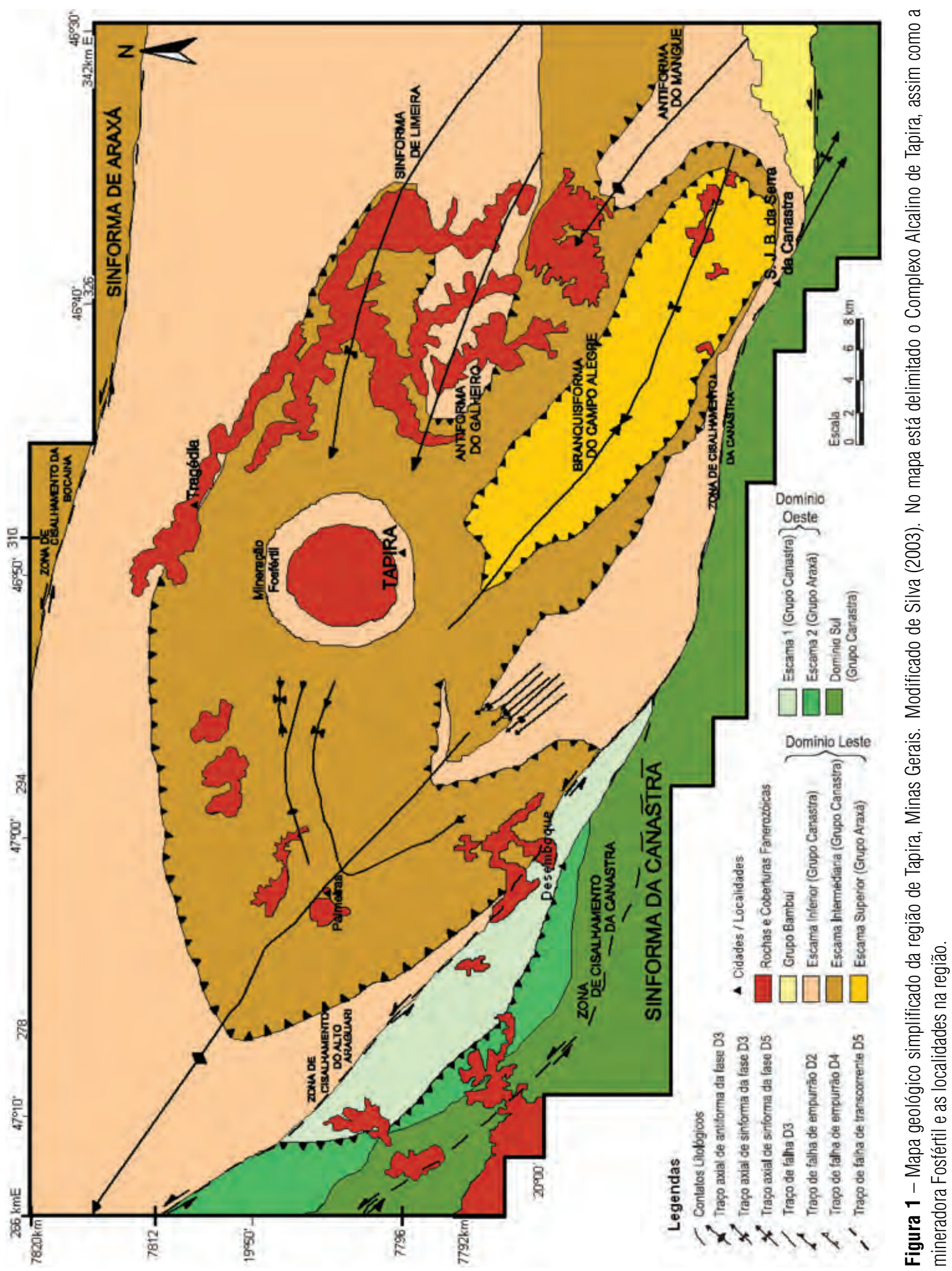


ritos (clinopiroxenito alcalino com biotita), com sienitos subordinados e rara presença de dunitos. Araujo et al. (2002) atribuem ao Complexo de Tapira uma predominância de cerca de 80\% de piroxenito.

Brod et al. (2005) identificaram duas unidades de rochas ultramáficas no Complexo de Tapira: a unidade B1, que ocupa a maior parte do centro da intrusão e a B2 que parcialmente a circunda ao norte. Há ainda uma intrusão de sienitos de granulação média (S) que ocorre na parte norte do complexo, assim como em pequenos plugs espaçados ao longo do domo (Fig. 2).

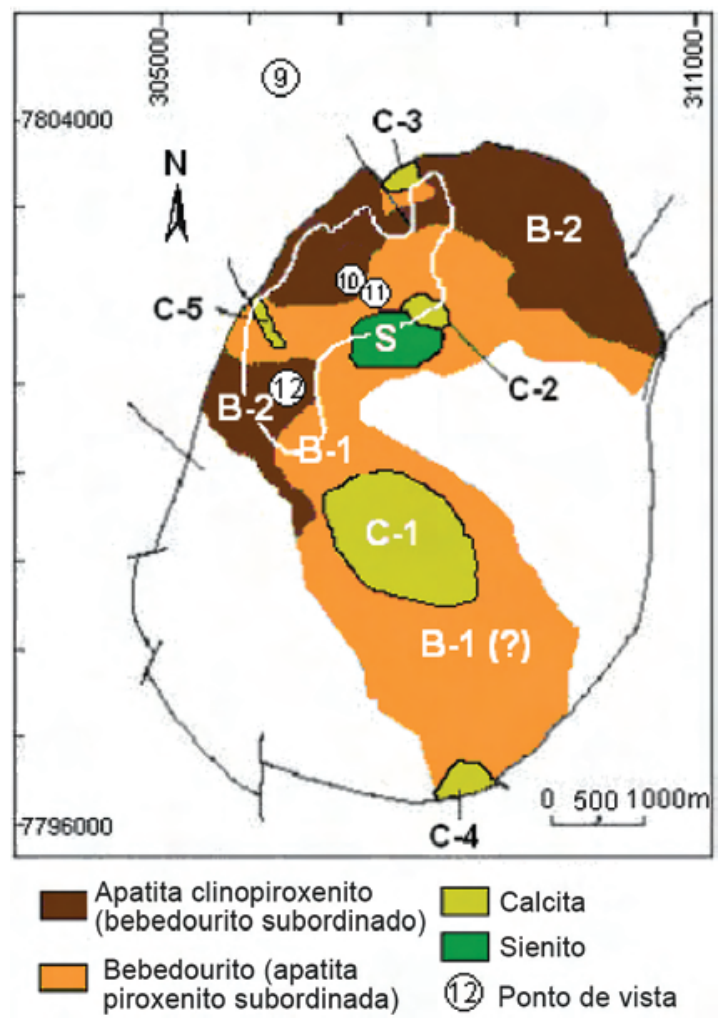

Figura 2 - Geologia do Complexo de Tapira com base em testemunhos de sondagem. Modificado de Brod (1999). Série Bebedourítica: B-1 - predominância de bebedouritos, B-2 - predominância de apatita piroxenitos; $S$ - sienitos. Séries Carbonáticas: C-1 a C-5. A linha branca representa o limite atual da mina. Os números 9, 10, 11 e 12 circunscritos indicam os pontos de vista realizados por Brod (1999).

Segundo Brod (1999) e Brod et al. (2005), os magmas primitivos do Complexo Alcalino de Tapira sofreram diferenciação durante sua ascensão, antes de sua intrusão final. Segundo esses autores, a prova disso é a presença de carbonatitos que teriam sido produzidos por imiscibilidade de líquidos e por cristalização fracionada. Esses mecanismos petrogenéticos produziram assinaturas geoquímicas e mineralógicas distintas na intrusão de Tapira.

No complexo alcalino, foram identificados cinco episódios de atividade carbonatítica. A maior e mais recente intrusão ob- servada (C1) ocorre em B1, na porção central da alcalina (Fig. 2). Os carbonatitos de C2 são espacialmente associados aos sienitos (S), ao norte do complexo; porém também ocorrem como diques dispersos e brechas ao longo da alcalina. C3 e C4 são intrusões menores de sovitos (cálcio-carbonatitos em textura grossa), ocorrendo próximos às margens norte e sul, respectivamente. C5, por sua vez, assume a forma de diques e veios de forma lenticular difundidos em um estágio tardio.

\section{LEVANTAMENTO GRAVIMÉTRICO}

0 estudo geofísico apresentado baseia-se num levantamento gravimétrico executado para o estudo específico do corpo intrusivo (Mantovani et al., 2005). 0 valor da gravidade obtido em cada estação foi referido à Rede Gravimétrica Fundamental Brasileira (RGFB - ON, 2009).

Na região de Araxá e Tapira não foram encontrados pontos de Referência de Níveis (RN) da rede de nivelamento do IBGE. Essas RN's são todas muito antigas e seus marcos foram destruídos. Todas as medidas gravimétricas do levantamento descrito foram referidas à Rede Gravimétrica Fundamental Brasileira (RGFB), tomando como referência a Estação Gravimétrica (EG) nº 012676 ARAXÁ, estação tipo "B", cota gravimétrica 978311.385 mGal, com precisão de 0,016 mGal (ex.: Mantovani et al., 2005).

$\mathrm{Na}$ aquisição de dados gravimétricos foram utilizados dois gravímetros, com precisão de 0,001 mGal e de 0,04 mGal.

0 estudo da anomalia gravimétrica depende do conhecimento da altitude exata das estações. Por isso, a elevação topográfica de cada estação gravimétrica foi determinada pelo método barométrico com base fixa. 0 erro relacionado a esse método é de $0,5 \mathrm{~m}, 0$ que corresponde a menos de 0,2 mGal no valor de $g$ obtido (McLintock et al., 1994). As medidas de topografia foram referidas diretamente à Rede de Nivelamento do IBGE.

As coordenadas de cada ponto foram determinadas através de receptores de posicionamento por satélite (GPS) com precisão variando entre 7 e $50 \mathrm{~m}$, dependendo da quantidade de satélites disponíveis, o que implica em uma incerteza inferior a 0,1 mGal para essas latitudes quando propagada para o valor da aceleração da gravidade.

Ao longo do levantamento foram instaladas ao todo 346 estações gravimétricas, distribuídas sobre 0 complexo alcalino e as regiões adjacentes (Fig. 3).

As estações gravimétricas distribuem-se em intervalos de medidas de $1 \mathrm{~km}$ sobre 0 domo alcalino, de cerca de $2 \mathrm{~km} \mathrm{so-}$ bre as regiões próximas ao domo, caracterizadas pela presença do anel de fenitização descrito (Fig. 1) e de $4 \mathrm{~km}$ para as estações mais distantes, obtendo-se assim uma área maior para 0 cálculo do campo regional.

Essa distribuição irregular dos dados e o crescente espaça- 


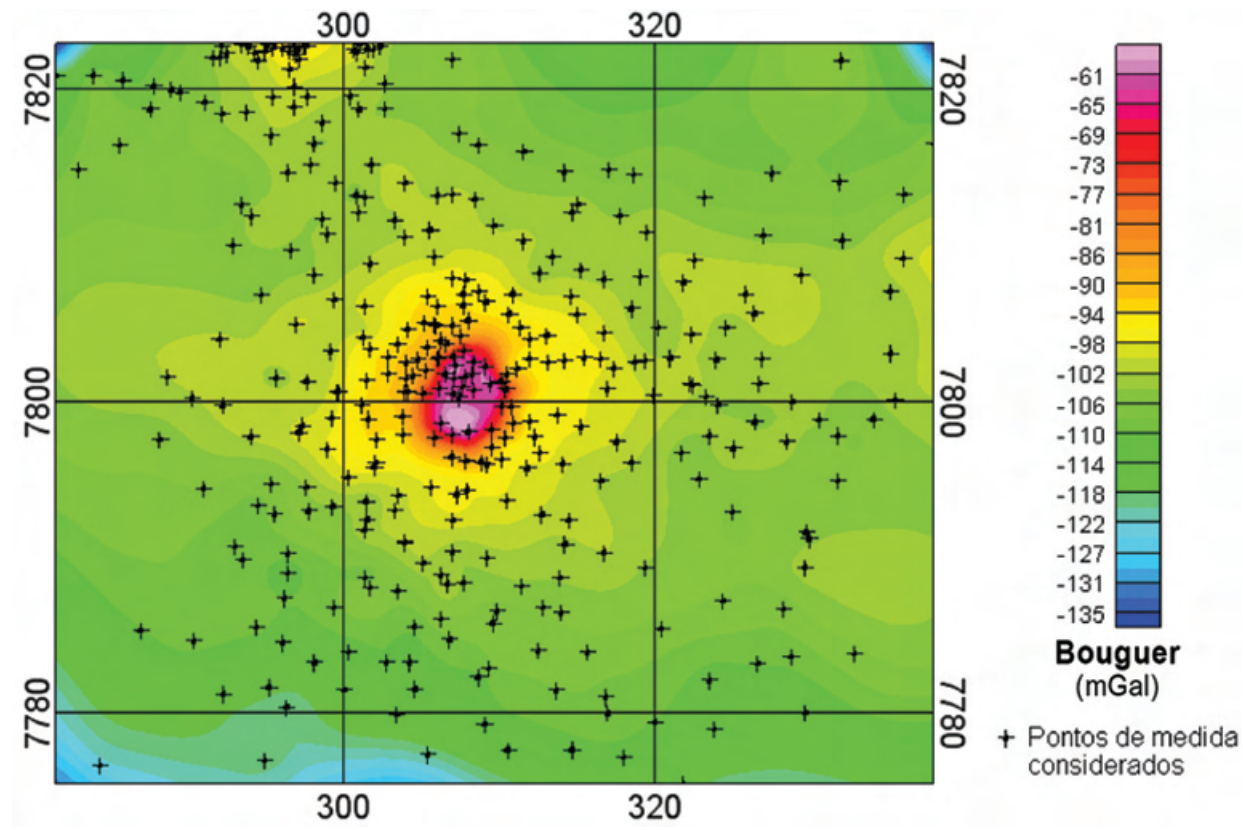

Figura 3 - Mapa com a distribuição das estações gravimétricas (cruzes pretas) instaladas sobre a anomalia Bouguer completa interpolada utilizando o método da mínima curvatura.

mento entre as estações gravimétricas, em função da distância do complexo alcalino, tornam extremamente importante a utilização de um método de interpolação adequado para evitar a distorção da anomalia gravimétrica resultante. Entre essas distorções, podem ser citados efeitos de bordas nos limites da malha de dados, extrapolação dos valores reais e até alteração do formato esperado para a anomalia gravimétrica.

0 campo gravimétrico regional observado, por sua vez, está associado às feições geológicas profundas e/ou de grande extensão, sendo sua amplitude diretamente proporcional à densidade volumétrica e à geometria observada para as litologias ou fácies regionais. Segundo Nelsi (2001), algumas das principais características do campo gravimétrico regional são: a continuidade, a suavidade e 0 grande comprimento de onda. Essas propriedades são importantes para definir o melhor método de separação regional-residual, e constituem um dos principais motivos que definiram o espaçamento entre as estações levantadas.

A importância em obter-se uma boa separação entre as componentes, residual e regional do campo gravimétrico reside, muitas vezes, na dificuldade em determinar o contato físico entre a rocha encaixante e o objeto de estudo, uma vez que este limite nem sempre é conhecido. Vale ressaltar também que o gradiente gravitacional não necessariamente reflete diretamente o limite do corpo. Exemplo disso ocorre em corpos intrusivos com bordas fenitizadas, como o do caso em estudo, que não possui resposta gravitacional expressiva.

\section{CORREÇÕES GRAVIMÉTRICAS}

0 cálculo das anomalias de gravidade em cada estação leva em consideração as medidas da aceleração da gravidade local " $\mathrm{g}$ ", da altitude, do efeito de maré sólida (Longman, 1959), e 0 valor teórico da gravidade calculado para o geoide de referência. 0 sistema de referência geodésico utilizado foi aquele definido em 1967 (GRS67), sendo a fórmula da gravidade dada por:

$$
\begin{aligned}
\gamma(\varphi)= & 97803185\left(1+5.27889510^{-3} \operatorname{sen}^{2} \varphi\right. \\
& \left.+2.3462 .10^{-5} \operatorname{sen}^{4} \varphi\right) \mathrm{mGal}
\end{aligned}
$$

onde $\varphi$ é a latitude geodésica da estação gravimétrica.

A anomalia Bouguer simples é calculada pela expressão

$$
\Delta g_{B}=g_{O B S}-\gamma(\varphi)+0,3086 \cdot h-2 \pi G \rho \cdot h
$$

onde $h$ é a altura referente ao ponto de medida em relação ao nível médio do mar no geoide, $G$ é a constante da gravitação universal e $\rho$ é a densidade de massa da crosta continental superior. Para os valores preconizados de $G=6.672 .10^{-11} \mathrm{~m}^{3} \mathrm{~s}^{-2} \mathrm{~kg}^{-1} \mathrm{e}$ $\rho=2670 \mathrm{~kg} / \mathrm{m}^{3}$. Observando-se a importância da medida da altura em cada estação conforme citado no item anterior.

A correção de relevo $\left(C_{R}\right)$ leva em conta o efeito gravitacional das massas topográficas que circundam uma estação gravimétrica. Quando essa correção $\left(C_{R}\right)$ é somada à anomalia Bouguer simples, tem-se a anomalia Bouguer completa, dada por:

$$
\Delta g_{B c}-\Delta g_{B}+C_{R}
$$


Valor este aqui utilizado na representação do campo gravimétrico.

\section{INTERPOLAÇÃO DA MALHA DE DADOS}

Segundo Yang et al. (2004), não há um método de interpolação restrita, mas sim o método mais adequado para cada caso. Por isso foram analisados os mapas de anomalia Bouguer completa obtidos por quatro métodos de interpolação: inverso da distância, triangulação, kriging e mínima curvatura.

\section{Inverso da Distância}

0 método do inverso da distância gera uma malha com distribuição regular a partir de dados com uma distribuição irregular. Neste método, os pontos interpolados são calculados através da aplicação de pesos aos dados medidos, sendo que a influência desses, no ponto calculado sobre a malha, decresce com sua distância.

A soma de todos os pesos atribuídos aos dados utilizados para 0 cálculo de um ponto da malha é sempre igual a um. Caso o ponto da malha a ser interpolado coincida com a posição de um dado medido, ele recebe peso um, e as demais observações, peso nulo. Neste caso particular, o valor interpolado coincide com 0 valor observado.

Para o caso contrário, o ponto interpolado $Z_{J}$, é obtido através da relação:

$$
Z_{J}=\frac{\sum_{I=1}^{n} \frac{Z_{I}}{h_{I J}^{\beta}}}{\sum_{I=1}^{n} \frac{1}{h_{I J}^{\beta}}}
$$

onde 0 coeficiente $h_{I J}^{\beta}$ é definido por:

$$
h_{I J}^{\beta}=\sqrt{d_{I J}^{2}+\delta^{2}},
$$

sendo $d_{I J}$ a distância entre o ponto $Z_{I}$, observado e o ponto da malha $Z_{J} ; \delta$, o parâmetro de suavização usado para atenuar 0 efeito bull's-eye (isolinhas concêntricas ao ponto de medida); $\beta$ é o parâmetro de amortecimento que amplifica a atenuação dos pontos distantes.

0 raio de busca dos dados observados para cada ponto interpolado é definido pelos valores de anisotropia utilizados, podendo ser considerada um busca com geometria elíptica ou circular, como no caso estudado. A definição do raio de busca é importante para situações em que há uma forte tendência na distribuição dos dados coletados ou no comportamento da propriedade física considerada.

Na Figura 4 observa-se o mapa interpolado utilizando este método.

\section{Triangulação}

\section{Diagrama de Voronoi}

Seja $S$ um conjunto com $N$ pontos amostrados. 0 Diagrama de Voronoi determina a região de influência para cada ponto $p_{i} \in S$, onde $i=1, \ldots, N$, tal que qualquer ponto $q$ contido no espaço definido pelo conjunto esteja mais perto de $p_{i}$ do que de qualquer outro ponto pertencente à $S$. Essas regiões de influência são denominadas Células de Voronoi (Fig. 5) e são definidas matematicamente por:

$$
V\left(s_{i}\right)=\left\{x \in \Re^{2}|\forall j \neq i,| s_{i} x|<| s_{j} x \mid\right\}
$$

onde $V\left(s_{i}\right)$ é a célula de Voronoi definida para o ponto de amostragem $s_{i}$.

Segundo Boissonnat \& Geiger (1992), ao traçar o segmento de linha entre os lados de um par de células de Voronoi, que possuam pelo menos um lado em comum, é obtida a triangulação de Delaunay. Na Figura 6 está disposto o diagrama de triangulação de Delaunay desenvolvido sobre o diagrama de Voronoi (linha tracejada). Segundo esses autores uma propriedade do Diagrama de Voronoi é que cada vértice da célula de Voronoi é circunscrito por um triângulo de Delaunay.

\section{Triangulação de Delaunay}

Neste trabalho, o método da triangulação foi aplicado considerando a utilização do algoritmo de Delaunay (Delaunay, 1934). Para isto, o algoritmo cria triângulos seguindo as seguintes propriedades:

1 - Propriedade do círculo local vazio: 0 círculo que circunscreve qualquer triângulo na triangulação de Delaunay não contém 0 vértice de qualquer outro triângulo em seu interior.

2 - Propriedade do ângulo máximo-mínimo: Considerando um tetraedro formado por quatro pontos experimentais, a diagonal desse tetraedro satisfaz a propriedade de máximo-mínimo se ela maximizar o valor mínimo dos seis ângulos internos aos dois triângulos formados.

3 - Propriedade da unicidade: Há um único arranjo da triangulação de Delaunay que se adéqua a um determinado conjunto de dados.

4 - Propriedade da bordas: Os triângulos mais externos à malha são gerados de tal forma que o conjunto de dados esteja sempre fechado de uma forma convexa.

0 esquema de interpolação da triangulação de Delaunay utilizada neste trabalho está disposto na Figura 7. Os pontos 


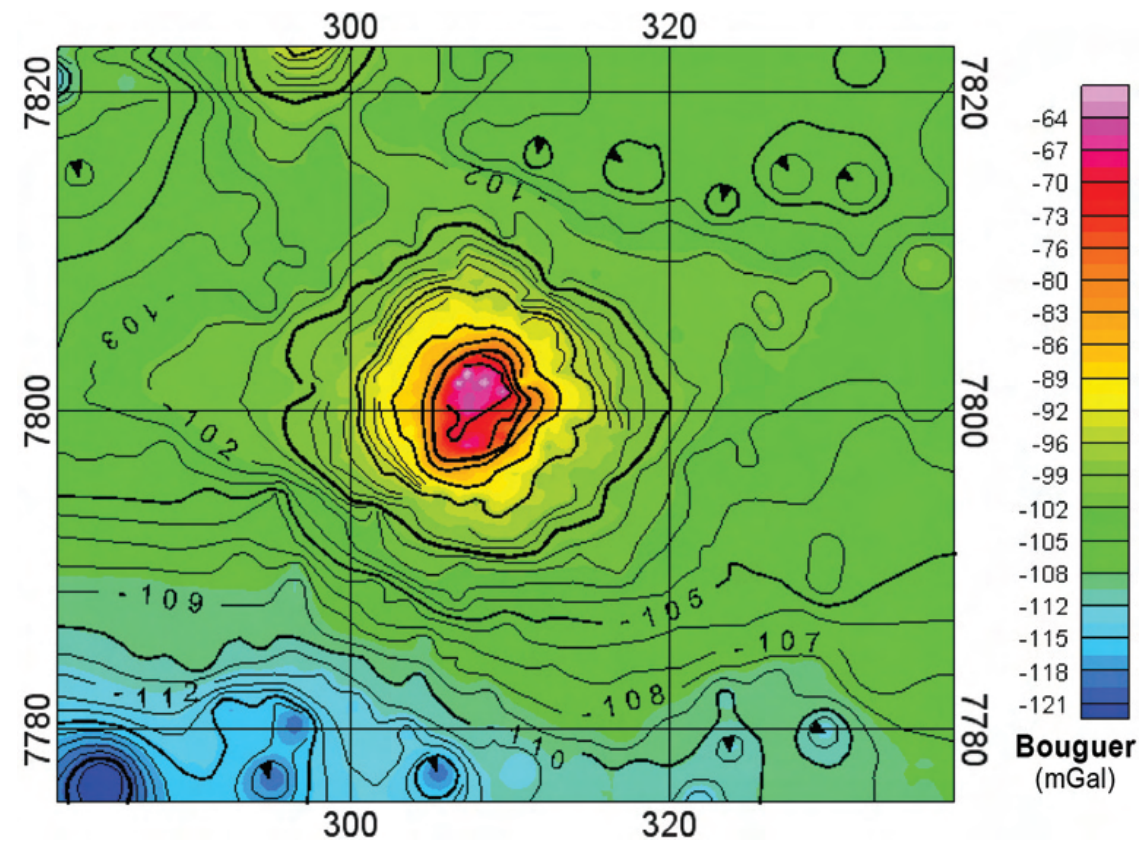

Figura 4 - Mapa da Anomalia Bouguer completa interpolado utilizando o método inverso da distância. As curvas de nível estão dispostas com intervalo de $1 \mathrm{mGal}$.

vermelhos indicam os dados observados, enquanto os demais vértices dos triângulos indicam os pontos interpolados. As circunferências traçadas na figura são utilizadas no confinamento dos triângulos, satisfazendo assim a restrição definida na propriedade do círculo local vazio. 0 círculo em cinza indica o ponto inicial da interpolação.

Diversas técnicas podem ser utilizadas na construção do algoritmo de interpolação para verificar se a propriedade do círculo local vazio é satisfeita ao longo da interpolação. Neste trabalho foi considerada a análise do determinante da matriz $M$ definida abaixo:

$$
\left|\begin{array}{llll}
A_{x} & A_{y} & A_{x}^{2}+A_{y}^{2} & 1 \\
B_{x} & B_{y} & B_{x}^{2}+B_{y}^{2} & 1 \\
C_{x} & C_{y} & C_{x}^{2}+C_{y}^{2} & 1 \\
D_{x} & D_{y} & D_{x}^{2}+D_{y}^{2} & 1
\end{array}\right|=
$$$$
\left|\begin{array}{l}
A_{x}-D_{x}, A_{y}-D_{y},\left(A_{x}^{2}-D_{x}^{2}\right)+\left(A_{y}^{2}-D_{y}^{2}\right) \\
B_{x}-D_{x}, B_{y}-D_{y},\left(B_{x}^{2}-D_{x}^{2}\right)+\left(B_{y}^{2}-D_{y}^{2}\right) \\
C_{x}-D_{x}, C_{y}-D_{y},\left(C_{x}^{2}-D_{x}^{2}\right)+\left(C_{y}^{2}-D_{y}^{2}\right)
\end{array}\right|>0,
$$

onde $A, B$ e $C$ são os vértices do triângulo de Delaunay selecionados no sentido anti-horário, e $D$ é o ponto da malha a ser verificado. 0 determinante da matriz $M$ será positivo apenas se 0 ponto $D$ estiver dentro da circunferência circunscrita ao triângulo $A B C$, contrariando assim a propriedade descrita.

Cada triângulo gerado define um plano sobre os nós da malha, sendo o declive e a elevação do triângulo determinado pelos três pontos originais (Malta \& Araújo, 2009). 0 resultado corresponde a uma teia de faces triangulares ao longo da malha (Fig. 8).

A implementação feita pelo Golden Software Surfer 8 para a interpolação do método da triangulação descrito utiliza como base 0 algoritmo apresentado por Guibas \& Stolfi (1985).

0 mapa interpolado utilizando esse método está disposto na Figura 9.

\section{Kriging}

0 método do kriging é um método de interpolação geoestatístico que considera tanto a distância quanto o ângulo de variação entre os pontos experimentais para então calcular os pontos interpolados. A eficiência dessa interpolação depende da especificação correta de diversos parâmetros que descrevem o semivariograma e 0 modelo de deriva.

Ao contrário do método do inverso da distância, a interpolação através do kriging pode levar em consideração diferentes funções de ponderação para o cálculo dos pontos interpolados. Para isso são levadas em consideração tanto a distância e orientação dos pontos de amostragem em relação aos nós das malhas; quanto à maneira na qual os pontos experimentais estão distribuídos espacialmente (Rugenski, 2006).

Antes da interpolação propriamente dita, o kriging calcula todas as funções de ponderação da distância. Para isso, é gerado um semivariograma experimental do conjunto de dados 


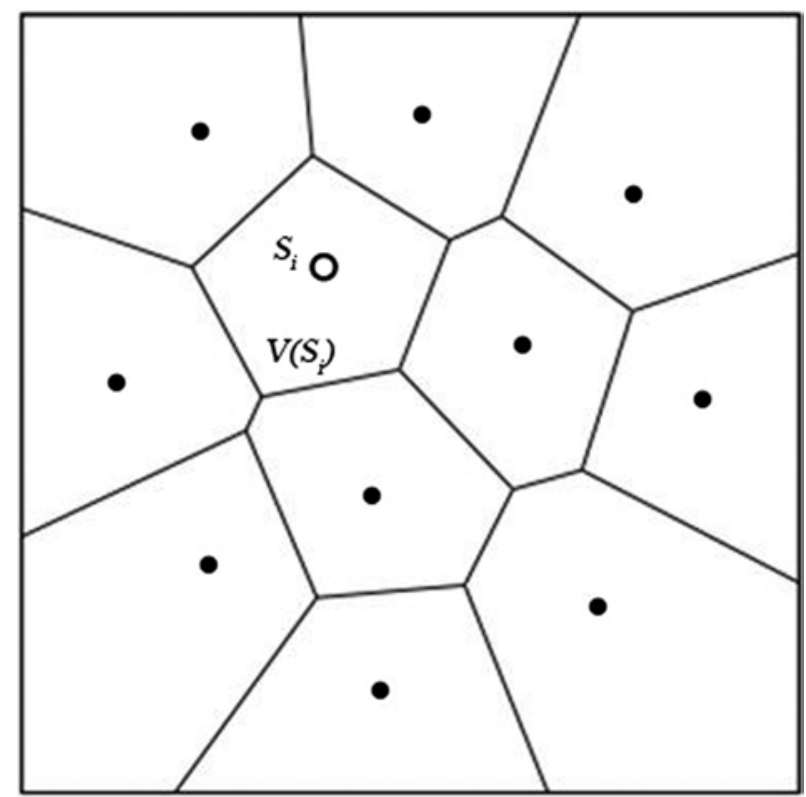

Figura 5 - Diagrama da célula de Voronoi $V\left(s_{i}\right)$ definida para o ponto $s_{i}$ considerado (vazado). Os círculos preenchidos sinalizam a localização dos demais pontos considerados. Modificado de Boissonnat \& Geiger (1992).

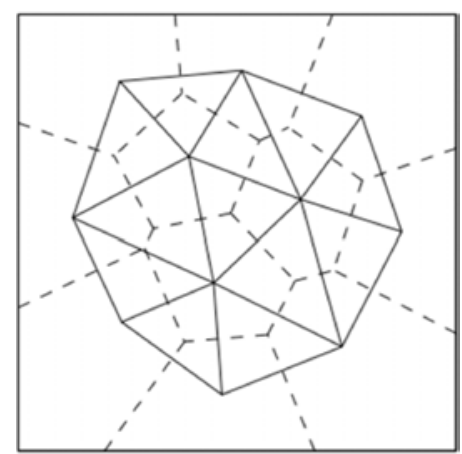

Figura 6 - Triangulação de Delaunay (linha contínua) disposto sobre o diagrama de Voronoi (linha tracejada). Modificado de Boissonnat \& Geiger (1992).

experimentais. Esse modelo permite determinar os pesos adequados a serem atribuídos para os pontos interpolados cada vez mais distantes dos pontos de medição. Porém é extremamente difícil determinar, precisamente, como um conjunto de dados varia em função da distância e da direção. Existem varias técnicas disponíveis para ajudar a determinar esse comportamento, sendo uma dos mais populares a análise da semivariância; adotada neste trabalho.

0 grau de dependência observada entre os pontos sobre uma determinada superfície é expresso pela propriedade da semivariância. A semivariância é definida pela metade da variação das diferenças medida entre todos os possíveis pontos espaçados a um intervalo constante, denominado lag (Bohling, 2005). Para uma distância igual a zero, a semivariância também é nula, já que não a diferença entre os pontos comparados. Porém, ao comparar pontos gradualmente mais distantes, 0 valor obtido para a semivariância também aumenta.

0 cálculo da semivariância é dada por (Bohling, 2005):

$$
\gamma(h)=\frac{1}{2 N(h)} \sum_{\alpha=1}^{N(h)}\left[z\left(u_{\alpha}+h\right)-z\left(u_{\alpha}\right)\right]^{2},
$$

onde $u$ é 0 vetor de coordenadas espaciais (componentes $x \mathrm{e}$ $y), z(u)$ representa a propriedade física analisada em função da localização espacial, $h$ representa o lag (espaçamento entre os pontos considerados) e $z(u+h)$ é o valor da propriedade física observada na coordenada defasada $(u+h)$.

Uma vez encerrado 0 cálculo da semivariância, é gerado 0 gráfico de semivariograma. Esse gráfico traça a função da semi- 


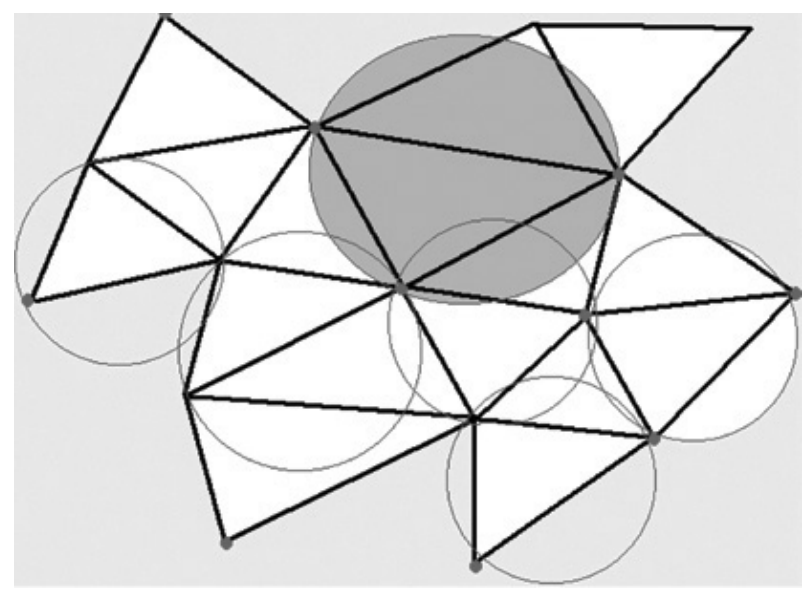

Figura 7 - Esquema de interpolação do método da triangulação feita pelo algoritmo de Delaunay. Os pontos indicam os dados experimentais, enquanto os demais vértices referem-se aos pontos interpolados. As circunferências traçadas são utilizadas pelo algoritmo para confinamento dos triângulos, ao passo que o círculo em cinza indica o ponto inicial da interpolação.

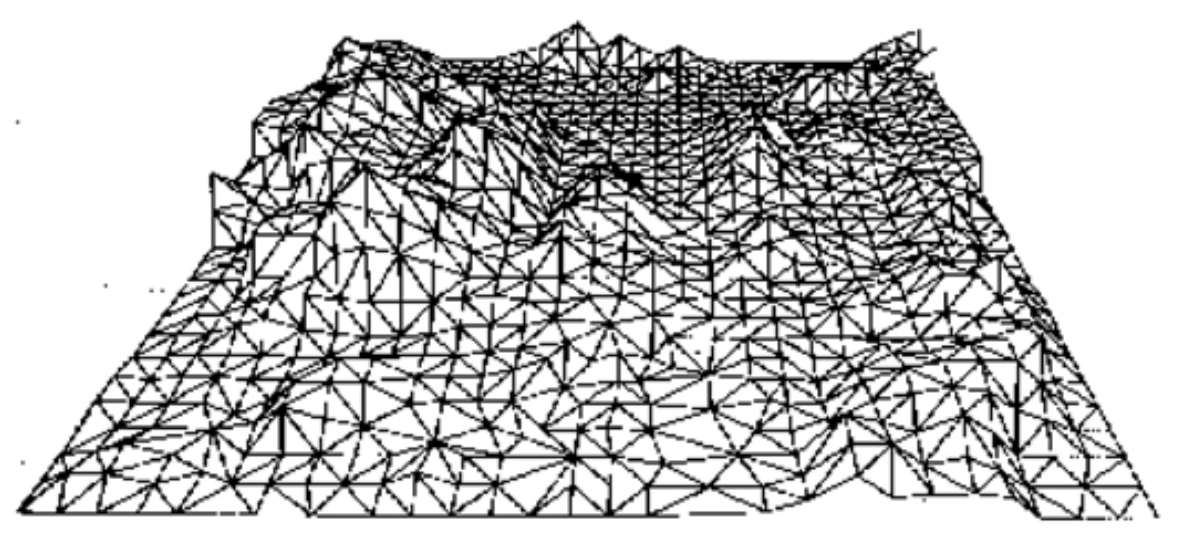

Figura 8 - Exemplo da estrutura da teia de faces triangulares desenvolvida na interpolação por triangulação. Modificado de Malta \& Araújo, 2009.

variância definida acima, em função da distância ( $/ a g$ ) considerada em cada etapa do cálculo (Bohling, 2005).

Como a função $\gamma(h)$ refere-se à metade do valor calculado para a variância, empregava-se o prefixo "semi" tanto para a função quanto para o gráfico gerado, no caso semivariograma (Barnes, 2004). Segundo esse autor, porém, o cálculo do kriging utiliza apenas 0 valor da função de semivariância, tendo o prefixo "semi" caído em desuso na literatura geoestatística, tanto referente à função $\gamma(h)$ quanto ao gráfico. Neste trabaIho, porém, optou-se por manter a presença do prefixo, evitando assim possiveis confusões entre as funções referidas.

0 semivariograma calculado para os dados utilizados neste trabalho está disposto na Figura 10. A linha preta no gráfico representa 0 gráfico obtido pelo cálculo da semivariância. Nota- se que esse gráfico possui um comportamento muito irregular. É então ajustado um modelo matemático com comportamento mais suave sobre 0 semivariograma (linha azul - Figura 10). Segundo Bohling (2005), este ajuste permite que 0 kriging utilize valores de lag diferentes dos considerados para os dados empíricos. Esse autor ressalta ainda que, para que os cálculos desenvolvidos pelo kriging tenham solução, é necessário que respeite certas propriedades matemáticas. Tecnicamente, o modelo ajustado no semivariograma precisa ser definido e um intervalo positivo, para que o sistema gerado pelas equações do kriging seja do tipo não-singular.

Muitas vezes, a correlação espacial dos dados experimentais não é a mesma para todas as direções, sendo essa característica 


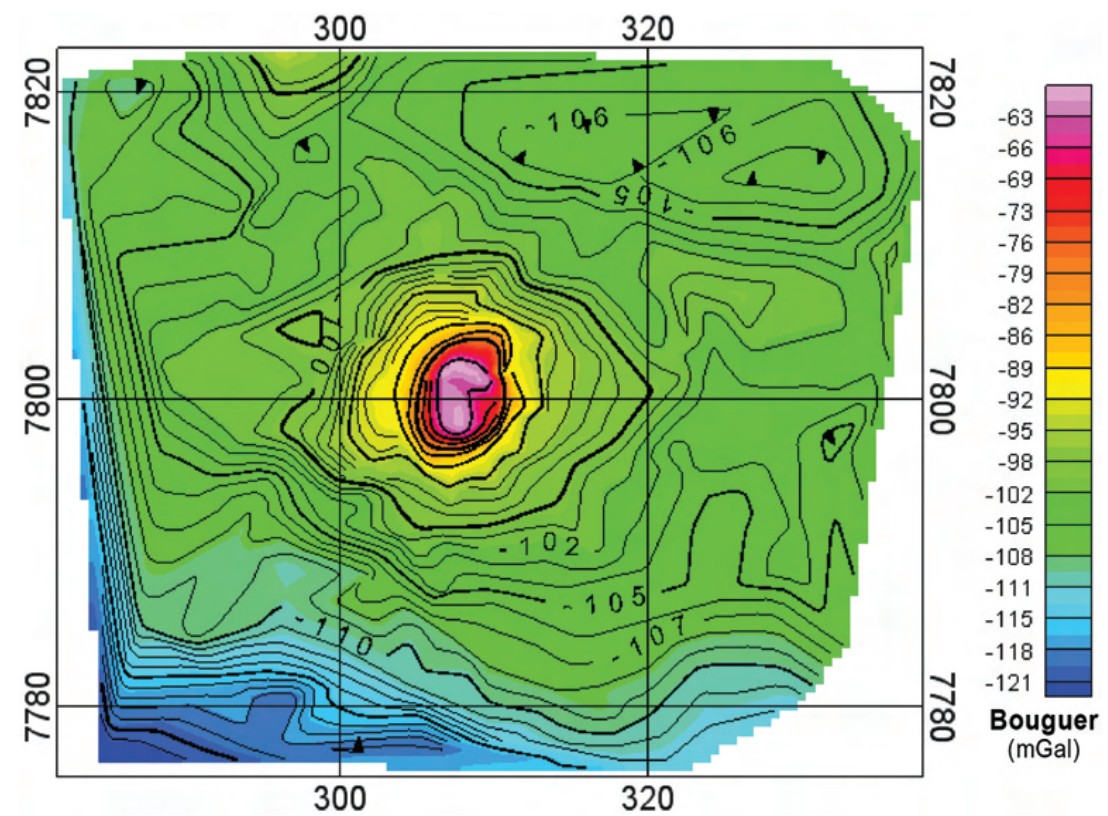

Figura 9 - Mapa da Anomalia Bouguer completa interpolado utilizando o método da triangulação. As curvas de nível estão dispostas com intervalo de 1 mGal.

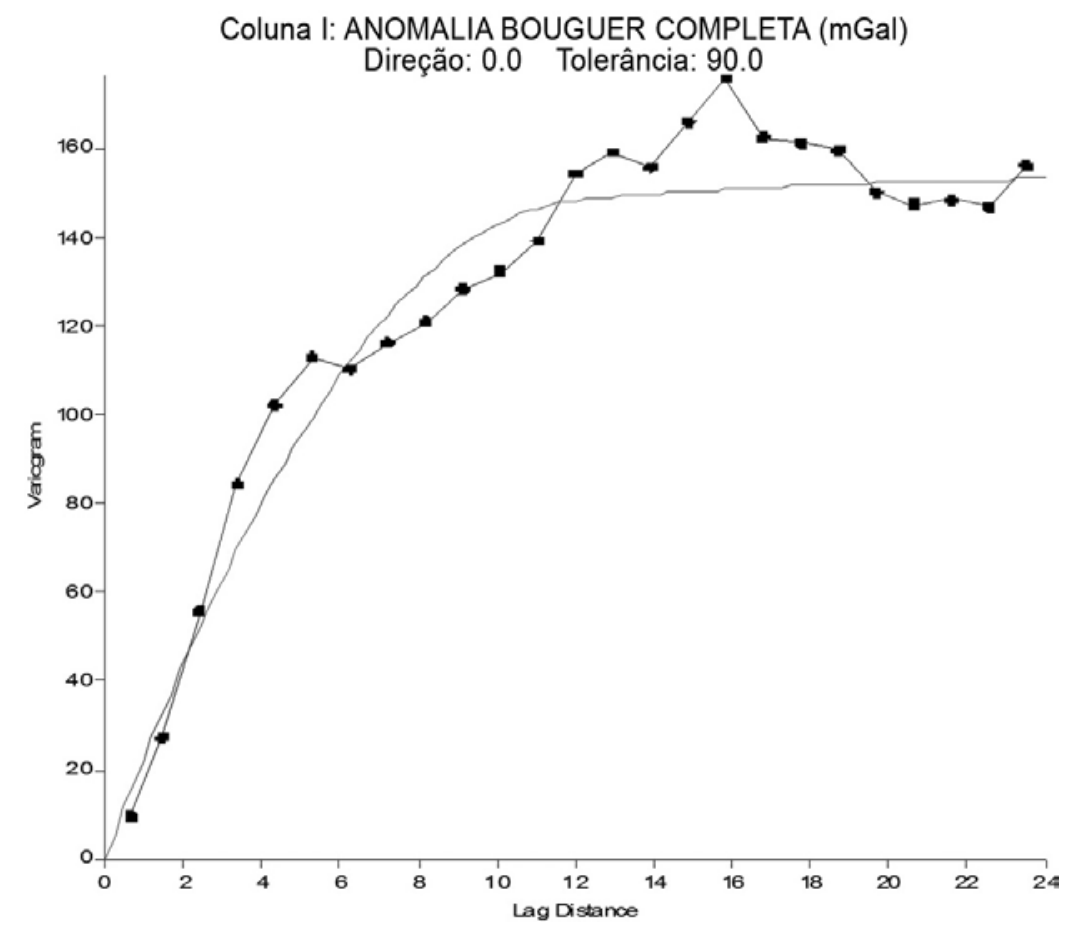

Figura 10 - Semivariograma utilizado na confecção da malha.

denominada anisotropia (Bohling, 2005). A partir da utilização do omni-directional, disponível no software utilizado, é possível medir o comportamento dos dados em todas as direções, identificando assim a presença ou não de anisotropia nos pontos amostrados (Barnes, 2004). Bohling (2005) ressalta ainda a importância de criar um semivariograma anisotrópico refletindo essa variação sempre que necessário, visando obter uma melhor interpolação da malha considerada. 
Segundo Barnes (2004), o semivariograma gerado pelo Golden Software Surfer 8.0 já considera as informações necessárias para descrever o comportamento do semivariograma em todas as direções. 0 gráfico deste representa um corte vertical do modelo 3D, já contendo, portanto, as informações referentes à anisotropia, quando existente.

0 Golden Software Surfer 8.0 permite a utilização de diversas funções para o ajuste do modelo matemático ajustado sobre o semivariograma (Barnes, 2004). Entre essas funções podem ser citadas esférica, exponencial, gaussiana, linear, quadrática, entre outras. Para a distribuição de dados considerados neste trabalho, o modelo matemático que melhor ajustou o comportamento experimental da variância foi obtido por duas funções quadráticas em série (Fig. 11).

Pela análise da Figura 11, nota-se que 0 gráfico gerado pelo cálculo da semivariância, a partir da distância em que lag = 12, tende a estabiliza em um patamar. 0 valor da semivariância associado a esse patamar é denominado sill, enquanto que 0 valor do lag é chamado de range (Bohling, 2005). Essa estabilização indica que, para valores maiores do que 0 range, a variância apresentará pouca alteração. Esse comportamento, porém, não é observado obrigatoriamente em todos os modelos, uma vez que este é intrinsecamente dependente das características dos dados amostrados.

0 modelo de kriging utilizado neste trabalho foi do tipo pontual, que estima os valores dos pontos interpolados sobre os nós das malhas. Porém o software utilizado oferece ainda a possibilidade da interpolação pelo método do kriging por blocos, que estima um valor médio de blocos regulares centrados sobre os nós da malha (Abramowitz \& Stegun, 1972).

Na Figura 11 encontra-se o mapa interpolado utilizando esse método.

\section{Mínima Curvatura}

0 método da mínima curvatura ajusta os dados observados por uma placa fina, linear e elástica, apresentando a menor curvatura possível no espaço Euclidiano. Esse método gera uma superfície mais lisa, enquanto se mantém o mais fiel possível aos valores dos dados.

0 método de interpolação da mínima curvatura foi desenvolvido por Briggs (1974). Este autor mostrou que se a curvatura total de uma superfície é minimizada se mantendo o mais fiel possível aos dados amostrados, então a superfície satisfaz a equação:

$$
\frac{\delta^{4} P}{\delta x^{4}}+2 \frac{\delta^{4} P}{\delta^{2} x \delta^{2} y}+\frac{\partial^{4} P}{\delta y^{4}}=0
$$

para todos os pontos interpolados. Considerando uma superfície interpolada com comportamento discreto, isso corresponde a resolver simultaneamente a equação de diferenças finitas:

$$
\begin{gathered}
P_{i+2, j}+P_{i, j+2}+P_{i-2, j}+ \\
2\left(P_{i+1, j+1}+P_{i-1, j+1}+P_{i+1, j-1}+P_{i-1, j-1}\right) \\
-8\left(P_{i+1, j}+P_{i-1, j}+P_{i, j-1}+P_{i, j+1}\right)+20 P_{i, j}=0,
\end{gathered}
$$

para cada ponto da malha interpolado ou que não é imediatamente adjacente aos limites da malha. Pontos da malha correspondentes aos dados experimentais são desconsiderados no cálculo da equação acima, uma vez que a interpolação se mantém fiel ao valor destes.

0 parâmetro de interpolação permite alterar a tensão da placa nas bordas ou na porção interna para atenuar a formação de pseudo-anomalias (Smith \& Wessel, 1990). Entretanto, vale mencionar que este método não constitui um interpolador exato (Yang et al., 2004).

0 mapa interpolado utilizando este método encontra-se na Figura 12.

\section{Comparação dos métodos descritos}

Ao comparar os mapas obtidos pelos métodos de interpolação considerados, nota-se que aqueles que apresentaram menor distorção do campo gravitacional foram traçados pelos métodos da mínima curvatura e do kriging.

Por isso, para uma análise mais efetiva entre os mapas interpolados por estes métodos, foram calculados os resíduos obtidos em cada um dos casos (Fig. 13), sendo os valores máximo e mínimo de 1,57 e -2,28 mGal respectivamente para kriging, e de 4,31 e -3,50 mGal para mínima curvatura.

\section{SEPARAÇÃO DAS COMPONENTES REGIONAL E RESIDUAL DO CAMPO GRAVIMÉTRICO Determinação das Componentes Regional e Residual}

A representação gravimétrica da anomalia Bouguer em qualquer região contém componentes de diferentes frequências, desde aquelas mais altas, características de corpos superficiais com diferentes geometrias, dimensões e densidades que contrastam com as rochas encaixantes, até aquelas de corpos intermediários e profundos. Para separar as componentes associadas às várias unidades geológicas, analisam-se os comprimentos de onda que contribuem para o sinal gravimétrico composto e utilizam-se filtros numéricos para isolar as componentes de cada faixa de frequência selecionada. Os filtros que selecionam os maiores comprimentos de onda ("passa baixa") são geralmente utilizados para determinar a componente gravimétrica regional, ou o campo 


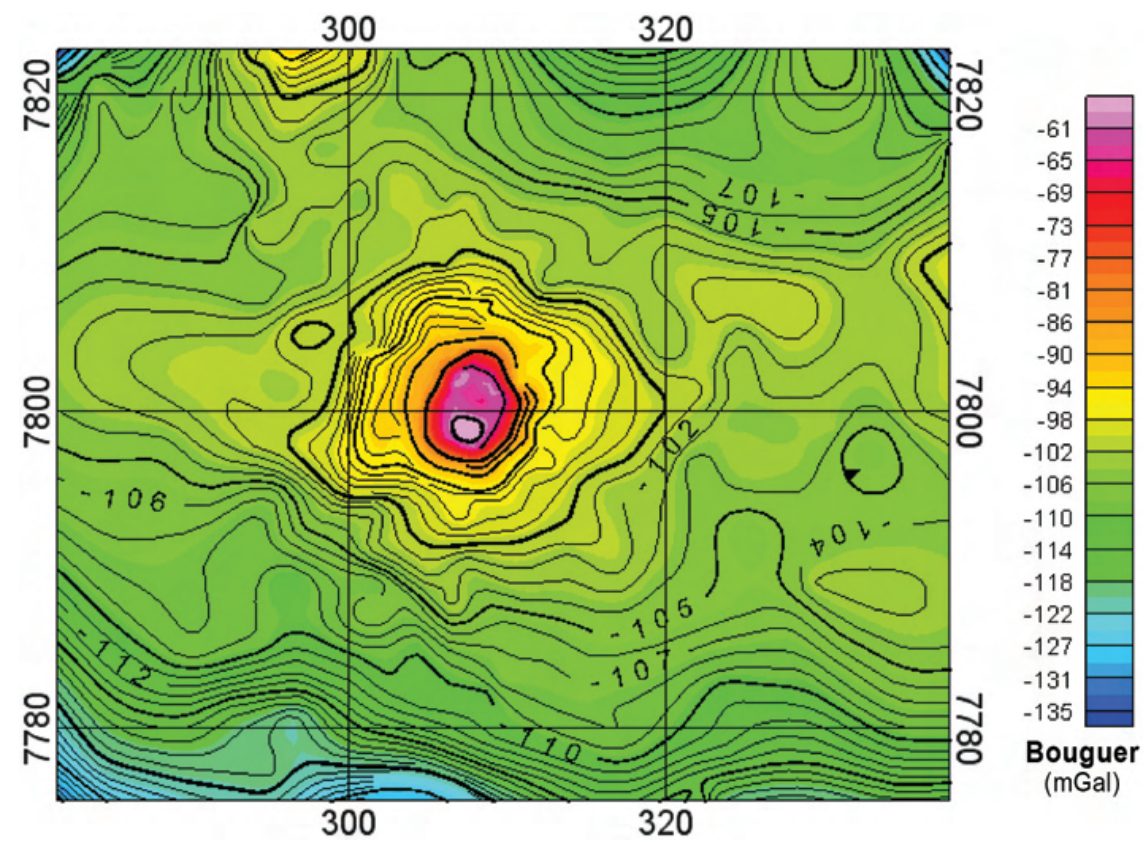

Figura 11 - Mapa da Anomalia Bouguer completa interpolado utilizando o método do kriging. As curvas de nível estão dispostas com intervalo de $1 \mathrm{mGal}$.

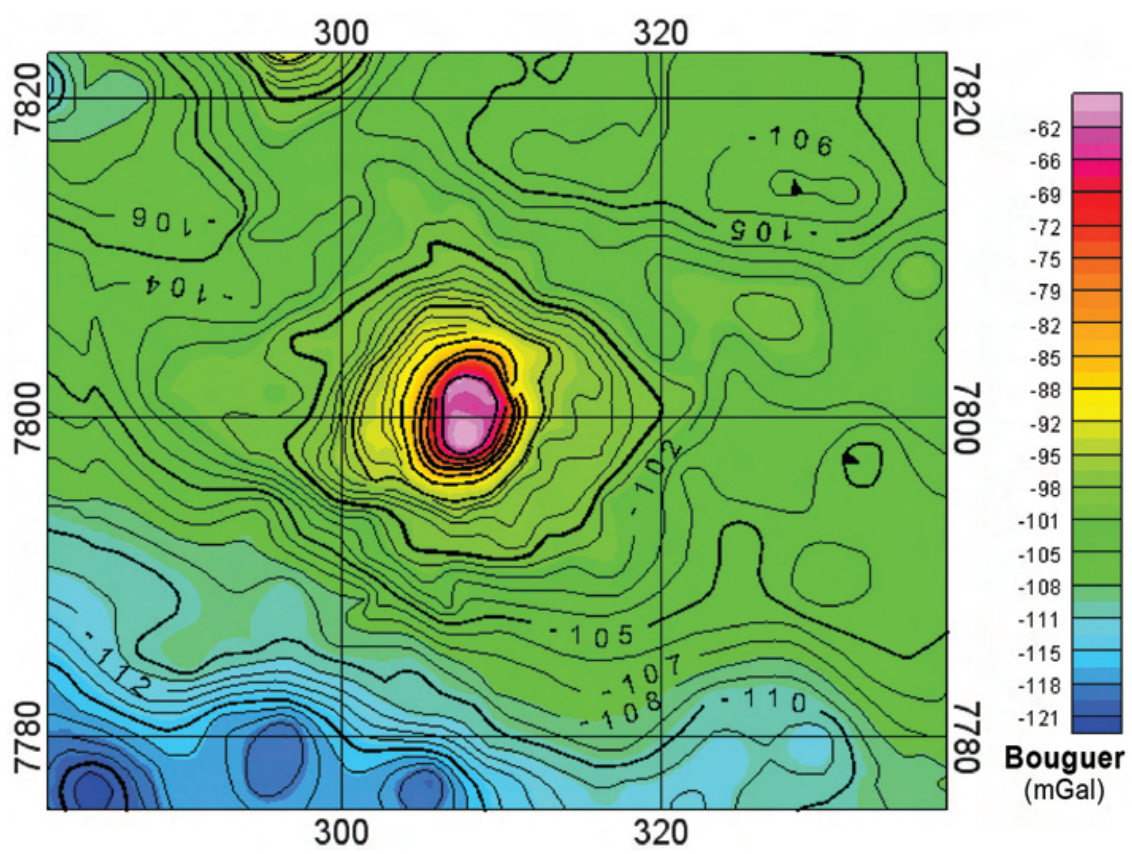

Figura 12 - Mapa da Anomalia Bouguer completa interpolado utilizando o método da mínima curvatura. As curvas de nível estão dispostas com intervalo de $1 \mathrm{mGal}$.

regional, que diz respeito aos corpos de dimensões relativamente grandes na escala em estudo.

Muitas vezes, a presença de um corpo com dimensões 3D significativas pode distorcer o campo regional e introduzir com- ponentes referentes apenas ao corpo isolado, como se observa no caso em estudo. A separação entre as componentes do campo gravitacional devem ser eliminadas a partir da utilização do método mais adequado ao campo observado. Neste trabalho 


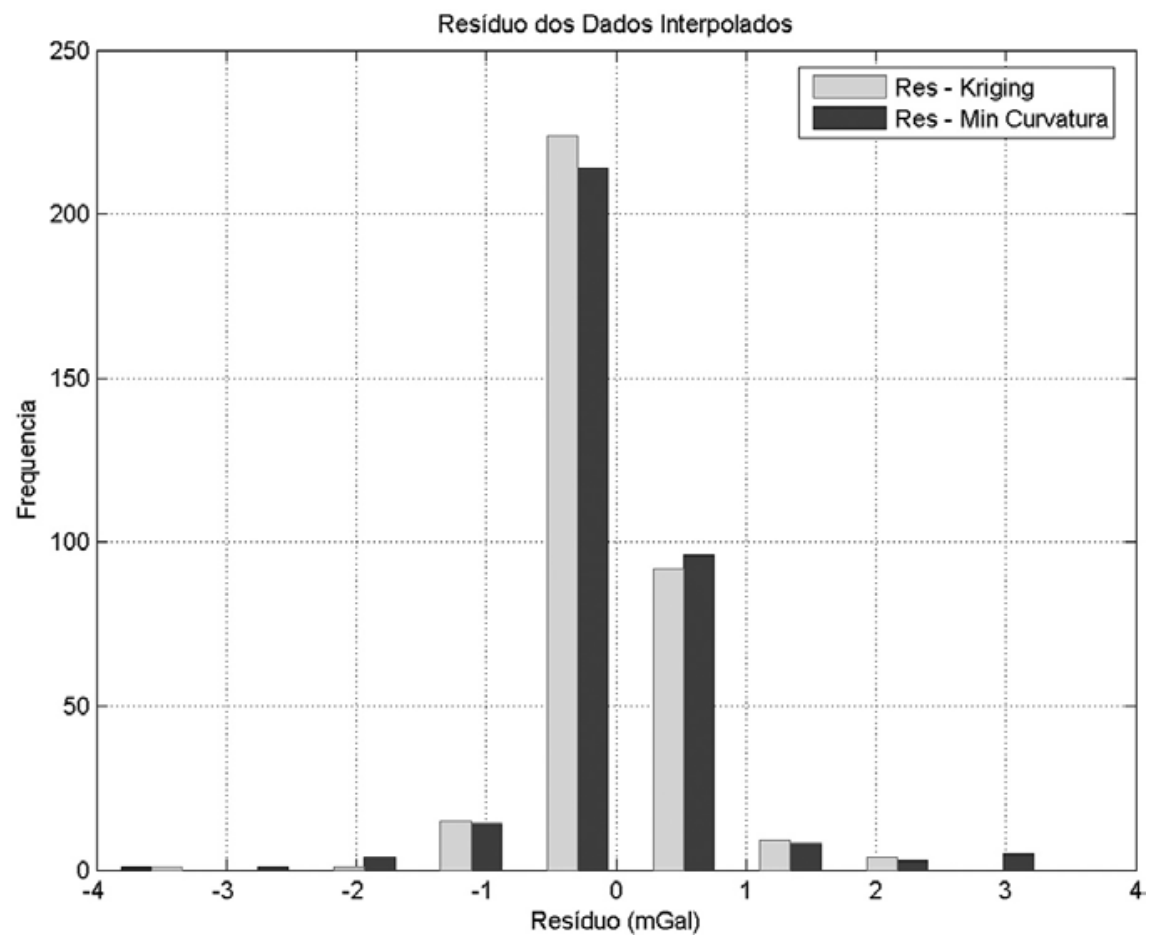

Figura 13 - Histograma dos resíduos obtidos pelos métodos do kriging e da mínima curvatura.

foram comparados o método do ajuste polinomial robusto descrito por Beltrão et al. (1991), o método da omissão (Rugenski et al., 2001), e a continuação para cima (upward continuation).

\section{Método do Ajuste Polinomial Robusto}

Segundo Gol'tsman (1977), a definição de um método de ajuste depende da especificação de uma função objetivo e de um critério de decisão. No método dos mínimos quadrados, a função objetivo é definida pela soma dos quadrados das diferenças entre 0 valor observado e 0 valor ajustado a cada ponto de amostragem. 0 critério de decisão empregado nesse método é a minimização da função objetivo.

Segundo Huber (1981), o estimador $M$ pode ser obtido minimizando a função objetivo:

$$
Q(c)=\sum_{i=1}^{N} u\left(\frac{r_{i}}{s}\right),
$$

onde $u$ é uma definição do método robusto, $s$ é 0 fator de escala e $r_{i}$ é o resíduo da $i$-ésima observação, definido por:

$$
r_{i}=g_{i}^{0}-f\left(x_{i}, y_{i}, z_{i}, c\right),
$$

sendo $g_{i}^{0}$ a $i$-ésima observação, $f(x, y, z, c) 0$ valor da função a ser ajustada no $i$-ésimo ponto $\left(x_{i}, y_{i}, z_{i}, c\right)$ e $c 0$ conjunto de parâmetros que definem a função $f$. Segundo Beltrão et al. (1991), o método dos mínimos quadrados pode ser visto como um estimador $M$ com função:

$$
u(v)=v^{2} .
$$

Considerando que a componente regional do campo pode ser aproximada por um polinômio de ordem $n$, definido nas coordenadas $x$ e $y$, tem-se que:

$$
f(x, y, z, c)=P_{n}(x, y, c),
$$

onde $c$ representa 0 conjunto de coeficientes do polinômio $P_{n}(x, y, c)$ considerado.

0 ajuste polinomial pelo método dos mínimos quadrados é feito considerando o campo gravimétrico total, não apenas a componente regional (Agócs, 1951; Simpson Jr., 1954; Abdelrahman et al., 1985). Nesse ajuste, geralmente assume-se que o comportamento regional pode ser aproximado por um polinômio de grau 1, 2 ou 3 (Rao et al., 1975; Abdelrahman et al., 1985). Porém, para polinômios com graus maiores, a componente residual modelada contém ainda influência da anomalia estudada, resultando assim em um campo residual de menor amplitude (Beltrão et al., 1991). Como o método dos mínimos quadrados considera que a soma de todos os resíduos gerados 
no ajuste é nula, esse método pode ainda gerar anomalias inexistentes, com valores contrários à anomalia residual esperada.

Beltrão et al. (1991) propõem que, para evitar os problemas associados com a utilização de graus maiores no ajuste pelo método dos mínimos quadrados, deve ser utilizado um método de ajuste mais robusto. Segundo esses autores, qualquer estimador $M$ que use uma função $u(v)$, definida na Equação 12 , que aumente mais lentamente do que $v^{2}$, configura um método mais robusto do que os mínimos quadrados.

0 método proposto esses autores define que a $(k+1)$-ésima aproximação de $c$ é obtida por:

$$
c^{(k+1)}=\left[A^{T} W^{(k)} A\right]^{-1} A^{T} W^{(k)} g^{0},
$$

onde $A$ é a matriz $N \times M$ cujos elementos são definidos por:

$$
a_{i j}=\frac{\partial P_{n}\left(x_{i}, y_{i}, c\right)}{\partial c_{j}},
$$

sendo 00 vetor nulo. A matriz diagonal de peso $W$, considerada na Equação 15, possui dimensão $N \times N$ sendo seus elementos definidos de forma a reduzir a distorção da amplitude, dados por (Beltrão et al., 1991):

$$
w_{i}^{(k)}=e^{-t^{2}}, \quad t<5,48,
$$

e

$$
w_{i}^{(k)}=A\left(\frac{t-5,48}{r_{M A X}}\right)^{2}, \quad t \geq 5,48,
$$

com

$$
t=\frac{0,6745 r_{i}^{(k-1)}}{s^{(k-1)}} .
$$

Na Equação 18, $r_{M A X}$ refere-se ao valor máximo absoluto do residual para $(k-1)$-ésima interação; $A$ é 0 fator de amplitude igual a 0,1 . 0 valor 5,48 foi escolhido como limite de $t$ porque corresponde aos valores virtualmente nulos da Equação 17 (Beltrão et al., 1991).

Através da aplicação de um ajuste polinomial robusto de diferentes graus aos dados gravimétricos da região estudada, interpolados tanto pela mínima curvatura quanto pelo kriging, observou-se que o polinômio robusto de grau 1 foi 0 que meIhor se ajustou, apresentando a menor influência residual da alcalina (Figs. 14 e 15).

\section{Método da Omissão}

0 método da omissão caracteriza-se pela retirada de estações gravimétricas sobre a área da anomalia de interesse e re-interpolação da malha. Ou seja, pontos da malha que apresentam componentes do campo gravimétrico geradas pela fonte da anomalia são retirados do banco de dados. A malha de dados é novamente interpolada, considerando apenas o campo regional gerado pelos dados restantes.

A escolha do valor da linha isoanômala que limita a área de exclusão leva em consideração diversos ensaios associando a área da curva de nível ao valor máximo da amplitude da anomalia, buscando assim minimizar a distorção para o menor número de pontos excluídos (Fig. 16). Nota-se que esse gráfico começa a estabilizar a partir da curva de $-90 \mathrm{mGal}$, estabilizando totalmente em -95 mGal (isoanômala limite escolhida).

Na área de exclusão, o campo gravitacional será definido pelo valor observado para as estações gravimétricas mais próximas. Esse processo pode subestimar o campo gravimétrico residual, atenuando assim a resposta observada para 0 corpo estudado. Dessa forma é preciso ressaltar a importância da escolha apropriada do método de interpolação antes da separação regionalresidual.

Para 0 Complexo Alcalino de Tapira foram eliminadas 75 estações (circunscritas à linha isoanômala selecionada) obtendose assim a componente gravitacional regional (Fig. 17) e residual (Fig. 18) do campo.

\section{Método da Continuação para Cima}

No método da continuação para cima (upward continuation), 0 valor observado para a gravidade nas estações medidas é recalculado considerando maiores distâncias da superfície do geoide, atenuando os pequenos comprimentos de onda e reduzindo o sinal das fontes pequenas e rasas (Blakely, 1996).

Segundo Blakely (1996), considerando que campo potencial foi medido sobre uma superfície plana $z=z_{0}$, a equação que define o comportamento desse campo para uma superfície $\Delta z>0$ acima da superfície de amostragem é dada por:

$$
\begin{gathered}
U\left(x, y, z_{0}-\Delta z\right)=\frac{\Delta Z}{2 \pi} \int_{-\infty}^{\infty} \int_{-\infty}^{\infty} \\
\frac{U\left(x^{\prime}, y^{\prime}, z_{0}\right)}{\left[\left(x-x^{\prime}\right)^{2}+\left(y-y^{\prime}\right)^{2}+\Delta Z^{2}\right]^{3 / 2}} \partial x^{\prime} \partial y^{\prime}, \\
\Delta Z>0 .
\end{gathered}
$$

Simplificando a Equação 20, obtém-se:

$$
\begin{gathered}
U\left(x, y, Z_{0}-\Delta Z\right)= \\
\int_{-\infty}^{\infty} \int_{-\infty}^{\infty} U\left(x^{\prime}, y^{\prime}, Z_{0}\right) \varphi_{u}\left(x-x^{\prime}, y-y^{\prime}, \Delta Z\right) \partial x^{\prime} \partial y^{\prime},
\end{gathered}
$$

onde

$$
\varphi_{u}(x, y, \Delta Z)=\frac{\Delta Z}{2 \pi} \frac{1}{\left[x^{2}+y^{2}+\Delta Z^{2}\right]^{3 / 2}} .
$$




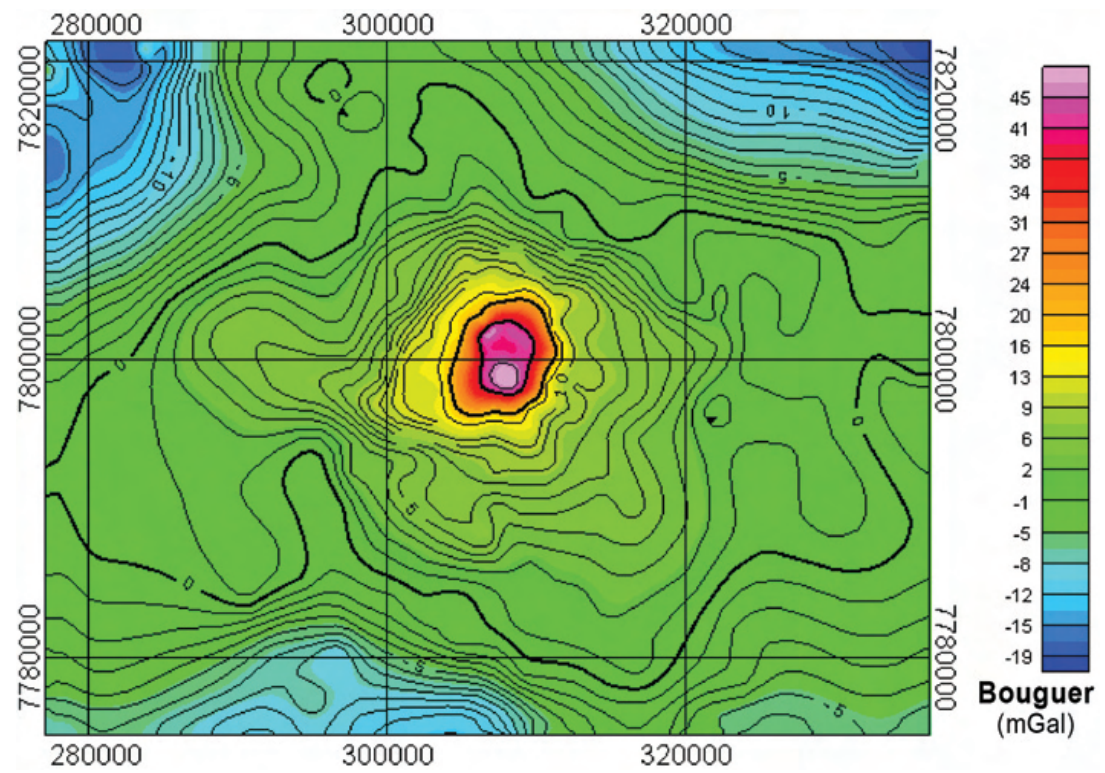

Figura 14 - Componente residual da anomalia Bouguer completa interpolada pela mínima curvatura após extração do ajuste polinomial robusto de grau 1.

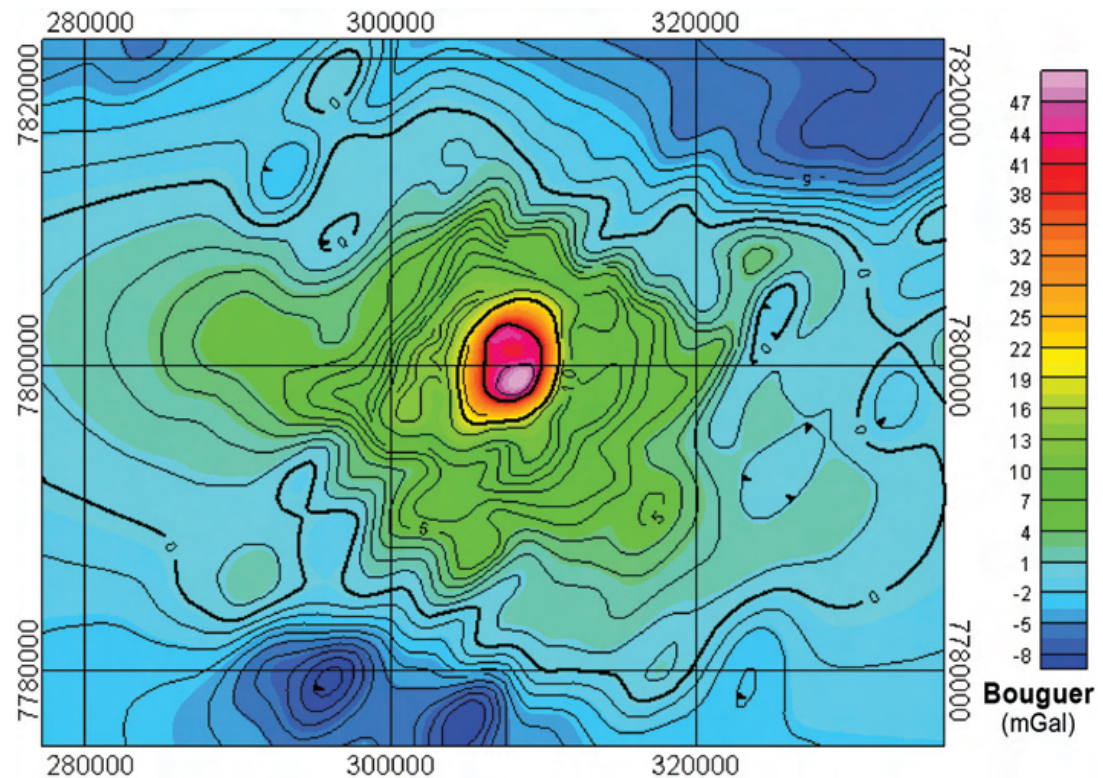

Figura 15 - Componente residual da anomalia Bouguer completa interpolada pelo kriging após extração do ajuste polinomial robusto de grau 1.

Substituindo $r=\sqrt{x^{2}+y^{2}+\Delta Z^{2}}$ na Equação 22, tem-se que:

$$
\varphi_{u}(x, y, \Delta Z)=\frac{1}{2 \pi} \frac{\delta}{\delta \Delta Z} \frac{1}{r} .
$$

Segundo Blakely (1996) o cálculo do campo gravitacional continuado para cima pode ser otimizado através da utilização da transformada de Fourier.
A transformada de Fourier do campo gravitacional continuado para cima é definido por:

$$
\Im\left[U_{u}\right]=\Im[U] \Im\left[\varphi_{u}\right] .
$$

A transformada de Fourier da função $\varphi_{u}$, definida na Equação 23, é dada por:

$$
\Im\left[\varphi_{u}\right]=-\frac{1}{2 \pi} \frac{\delta}{\delta \Delta Z} \Im\left[\frac{1}{r}\right] .
$$




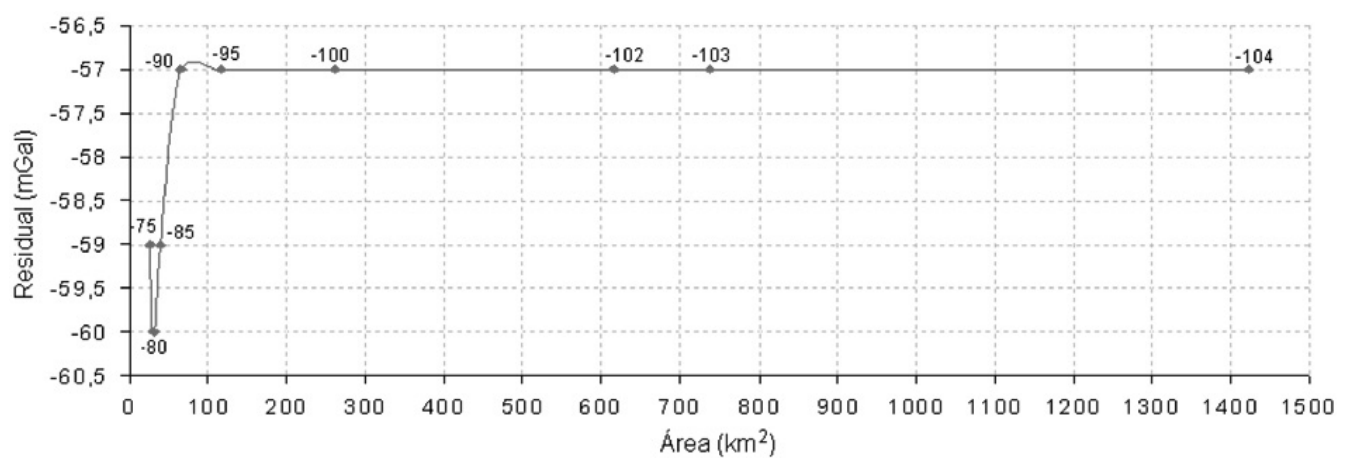

Figura 16 - Gráfico obtido para os ensaios realizados. 0 valor ao lado dos pontos refere-se à linha isoanômala correspondente.

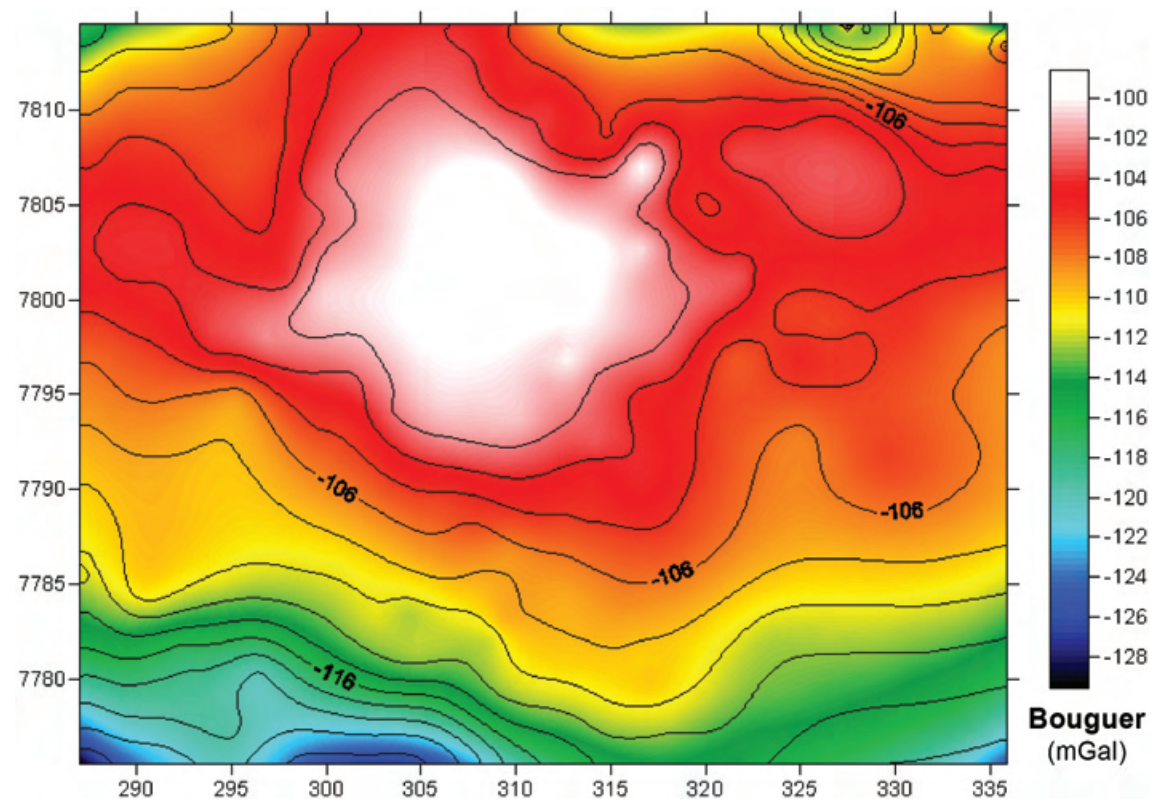

Figura 17 - Componente regional da anomalia Bouguer obtida pelo método da omissão. As linhas de contorno estão com espaçamento de 2 mGal.

A solução da transformada de Hankel de ordem zero definida por Bracewell (1965) diz que:

$$
\Im\left[\frac{1}{r}\right]=2 \pi \frac{e^{|k|\left(z_{0}-z^{\prime}\right)}}{|k|}, \quad Z^{\prime}>Z_{0},|k| \neq 0 .
$$

Logo, a Equação 25 pode ser reescrita como:

$$
\Im\left[\varphi_{u}\right]=-\frac{\delta}{\delta \Delta Z} \frac{e^{|k| \Delta Z}}{|k|}=e^{-\Delta z|k|}, \quad \Delta Z>0 .
$$

0 campo gravimétrico continuado para cima, definido no domínio do espaço, é obtido então pela equação:

$$
\Im\left[U_{u}\right] \stackrel{F F T}{\longrightarrow} U_{u} .
$$

Foram feitos diversos ensaios considerando valores crescentes da altitude em relação ao plano de observação. Visando uma melhor comparação entre as componentes gravitacionais isoladas para essas alturas, foi traçado um perfil sobre as anomalias isoladas durante esses ensaios (Fig. 19). A menor altitude a não apresentar influência da alcalina foi no mapa de campo regional foi de $40 \mathrm{~km}$.

Ao subtrair o mapa regional adquirido para a altitude de 40 km (Fig. 20) da anomalia Bouguer completa (Fig. 14), obtevese o mapa referente ao campo residual originado por esse método (Fig. 21).

\section{Comparação entre os Métodos da Omissão, do Ajuste Polinomial Robusto e da Continuação para Cima}

Para comparar as anomalias isoladas pelo ajuste polinomial robusto, o método da omissão e a continuação para cima, foi 


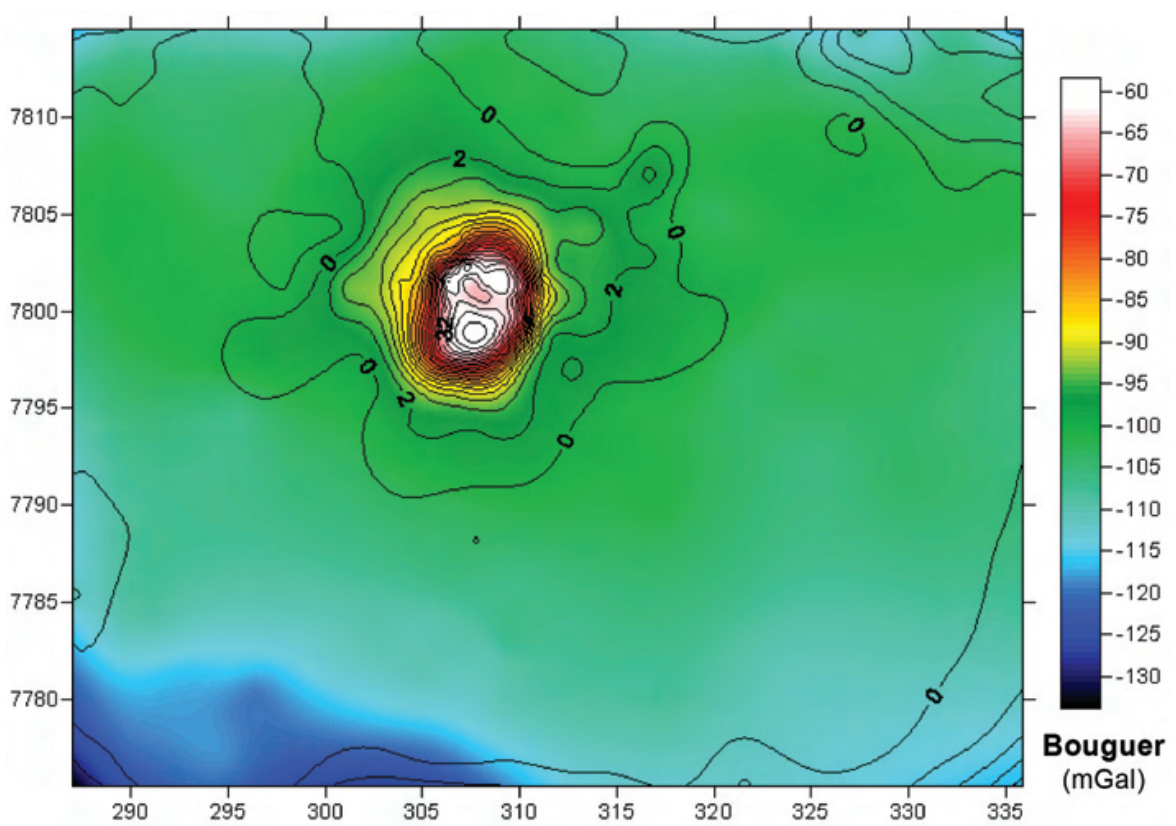

Figura 18 - Componente residual da anomalia de Tapira obtida pelo método da omissão. As linhas de contorno estão com espaçamento de 2 mGal.

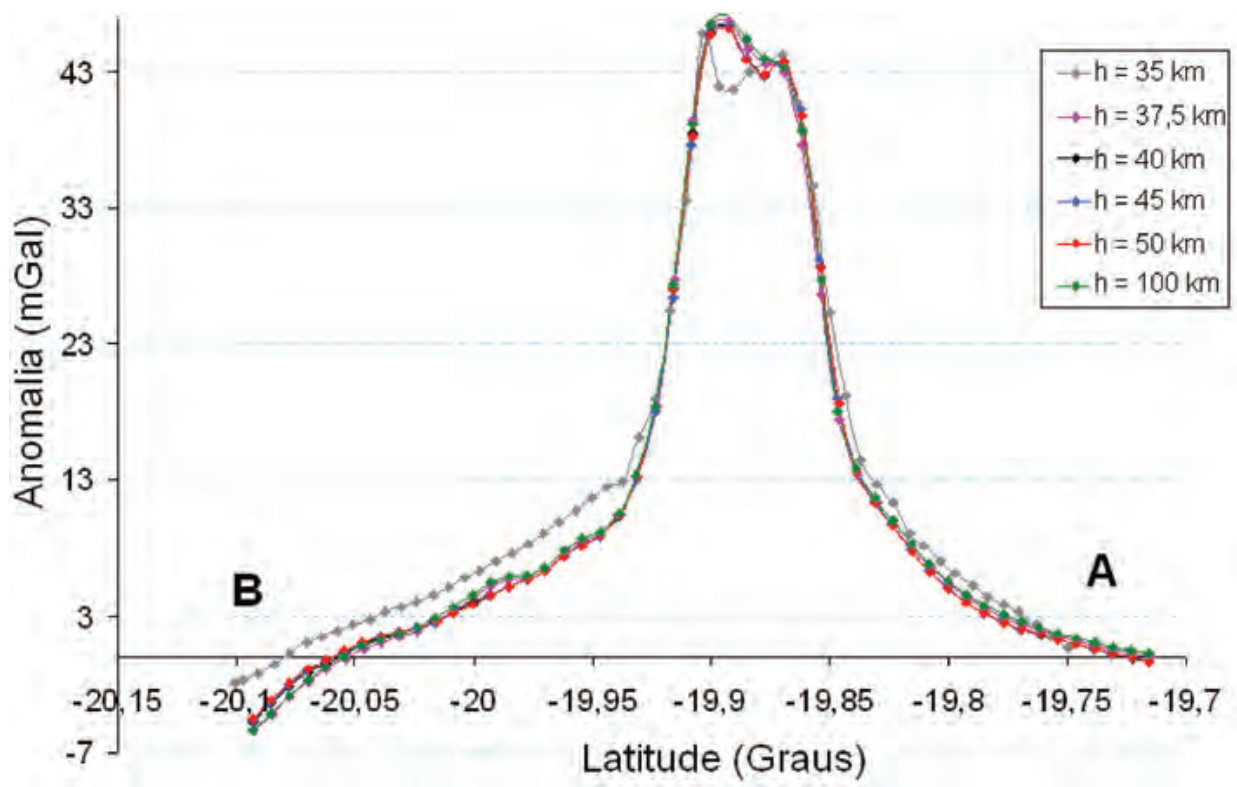

Figura 19 - Gráfico dos valores obtidos pelo perfil A-B traçado sobre a anomalia isolada pelo método da continuação para cima, considerando diferentes alturas.

traçado um perfil A-B comum aos três casos. A localização do perfil considerado encontra-se na Figura 22. Os valores obtidos para esses perfis, nos diferentes mapas, estão dispostos no gráfico da Figura 23.

A anomalia isolada pelo ajuste polinomial robusto apresentou valor máximo de 47,96 mGal para a mínima curvatura, e 49,84 mGal para o kriging, para o método da omissão esse valor foi de 44,87 mGal, e de 46,15 mGal para o método da continuação para cima. A diferença obtida entre os picos de anomalia pelo ajuste polinomial robusto utilizando o kriging e a mínima curvatura foi de $1,88 \mathrm{mGal}$. Já para os métodos da continuação para cima e 0 método da omissão, a diferença entre estes e 0 ajuste polinomial robusto utilizando o kriging foi de 4,01 mGal e 4,97 mGal, respectivamente. 


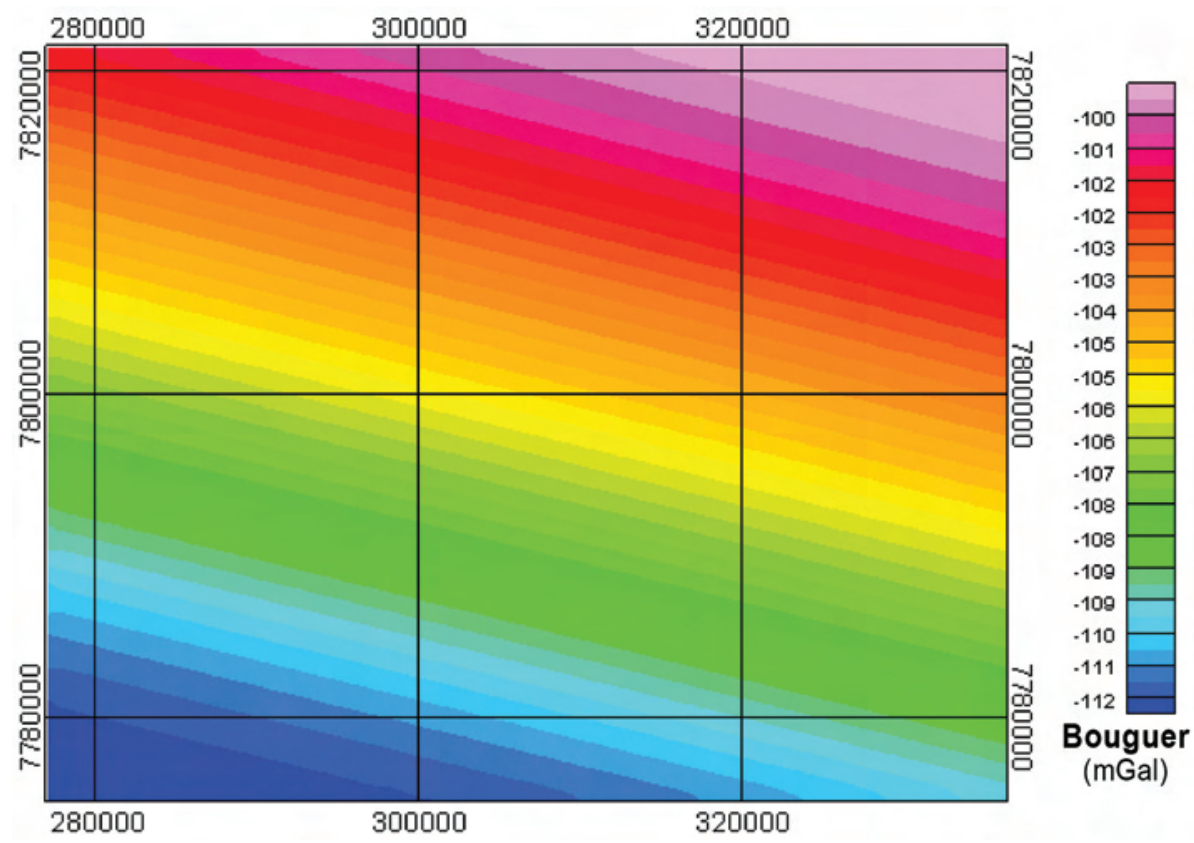

Figura 20 - Componente regional da anomalia Bouguer obtida pelo método da continuação para cima, considerando altura de $40 \mathrm{~km}$.

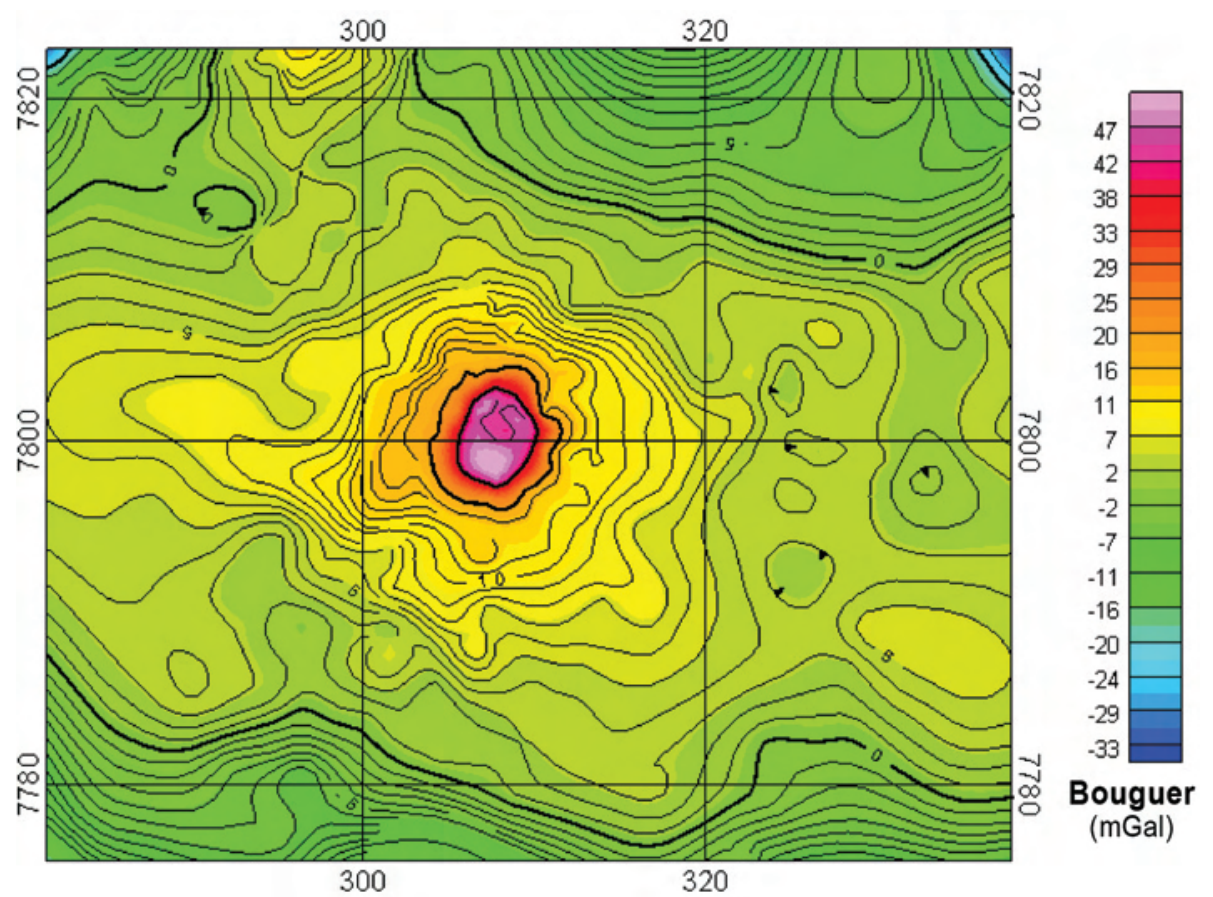

Figura 21 - Componente residual da anomalia obtida pelo método da continuação para cima, considerando altura de $40 \mathrm{~km}$. As linhas de contorno estão com espaçamento de 2 mGal.

\section{DISCUSSÃO}

0 mapa obtido pela interpolação utilizando o método de inverso da distância (Fig. 4) apresentou uma tendência circular muito forte, concêntrica aos pontos de medições. Esse padrão é conhecido como efeito de bull's-eye (Yang et al., 2004). Considerando que o regional gravitacional é caracterizado por um comportamento suave e contínuo (Nelsi, 2001), esse padrão gerou 


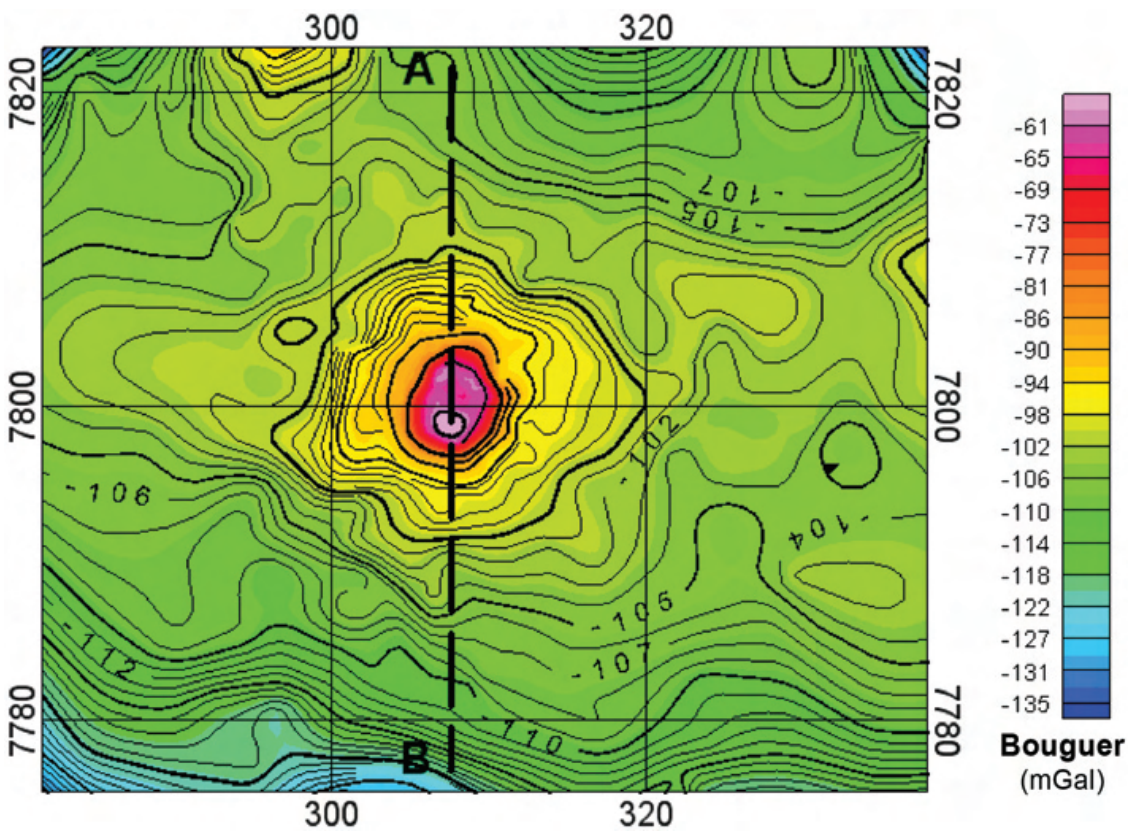

Figura 22 - Mapa da anomalia Bouguer completa interpolado pela mínima curvatura. As linhas de contorno estão espaçadas com intervalo de $1 \mathrm{mGal}$. 0 perfil A-B disposto no mapa assinala o perfil considerado.

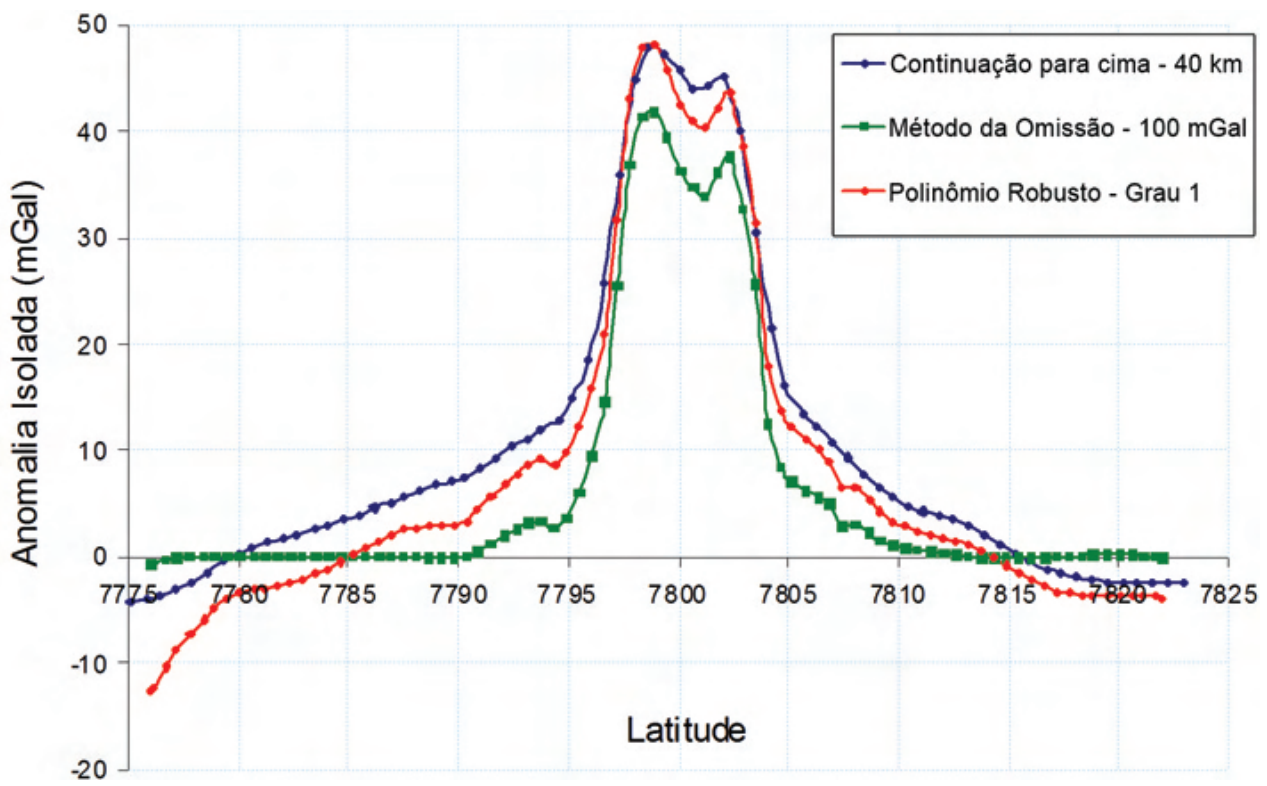

Figura 23 - Gráfico dos valores obtidos pelo perfil A-B traçado sobre a anomalia isolada pelos métodos da continuação para cima para altura de 40 km, método da omissão considerando isolinha de 100 mGal e ajuste polinomial robusto de grau 1.

falseamento da resposta esperada. Esse padrão é observado principalmente na parte sul e nordeste do mapa interpolado. Nota-se também na anomalia referente à intrusão alcalina, a presença de bordas mais irregulares do que as esperadas, sendo esse efeito visível principalmente na linha de contorno de $95 \mathrm{mGal}$.
Na malha interpolada pelo método da triangulação é possível observar anomalias com padrão angular, principalmente nas áreas e que os pontos encontram-se mais afastados. Esse padrão pode ser observado também próximo da anomalia gravimétrica referente à alcalina, ficando evidente principalmente na linha de 
contorno de $100 \mathrm{mGal}$. 0 campo regional, assim como para 0 método do inverso da distância, não apresenta o comportamento contínuo e suave esperado.

0 método da triangulação não interpola os dados além dos limites dos triângulos gerados pelos pontos de medidas, gerando assim um mapa com uma componente regional menor do que as demais interpolações. De fato, o mapa interpolado por esse método não apresentou efeito de borda, que é caracterizado pela extrapolação gerada pela interpolação em áreas sem pontos de medidas.

Os mapas de campo Bouguer interpolados pelos métodos da mínima curvatura e do kriging apresentaram um comportamento suave e contínuo (Figs. 11 e 12). De fato, os mapas obtidos por esses dois métodos não apresentaram pseudo-anomalias ao redor dos pontos de medidas ou alteração da tendência esperada para o comportamento do campo regional, como observado para os mapas interpolados pelo inverso da distância e pela triangulação.

A principal diferença para o campo Bouguer interpolado pela mínima curvatura e pelo kriging está no comportamento do campo próximo às bordas do mapa. Essa diferença é visível principalmente ao sul dos mapas gerados e pode ser explicada pela presença de efeitos de bordas, geradas pela interpolação da mínima curvatura. Daí a importância em se comparar os resíduos gerados por essas interpolações.

Os valores de máximo e mínimo dos resíduos obtidos (Fig. 13) foram de 1,57 e -2,28 mGal para 0 kriging, e de 4,31 e $-3,50$ mGal para a mínima curvatura. Pela análise da distribuição gaussiana destes, nota-se que o resíduo obtido pela interpolação do kriging concentra-se principalmente próximo ao zero, enquanto que os resíduos referentes à mínima curvatura apresentam um maior espalhamento, atingindo assim valores mais elevados. Por essa análise, pode-se concluir que o método de interpolação que obteve a melhor resposta para o caso em estudo foi 0 kriging.

No método da omissão, observa-se que o mapa da componente regional ainda apresenta influência do corpo intrusivo (Fig. 17), não isolando totalmente a anomalia. De fato, a amplitude da anomalia isolada por esse método é menor do que 0 esperado, 0 que explica 0 valor mais baixo observado no perfil A-B para 0 gráfico referente a esse método (Fig. 23). 0 método da omissão, provavelmente apresentaria uma resposta melhor se aplicado a uma malha de dados mais densa, considerando uma área maior para o regional, possibilitando uma melhor remoção dos pontos de medidas sobre a anomalia considerada.

Ao analisar os ensaios pelo método da continuação para cima (Fig. 19) nota-se que para altitudes menores do que $40 \mathrm{~km}$ o perfil apresenta valores mais elevados nas laterais. 0 que indica, assim como no método da omissão, que a anomalia residual não foi completamente isolada.

Para alturas maiores, notou-se que 0 comportamento do gráfico apresenta pouca variação. Ao comparar os perfis obtidos para as alturas de $50 \mathrm{~km}$ e $100 \mathrm{~km}$, observa-se que a diferença entre os picos é amenizada. 0 que pode ser explicado pela atenuação do sinal associado à intrusão carbonatítica, que possui menor comprimento de onda se comparado à rocha alcalina.

Considerando os resultados obtidos pelos ensaios realizados, conclui-se que a altura que melhor isolou a contribuição gravimétrica associada à rocha alcalina foi de $40 \mathrm{~km}$.

No perfil considerado para os três métodos (Fig. 23), a anomalia apresenta dois picos distintos assim como limites horizontais coincidentes (latitude: $-19,93^{\circ} \mathrm{e}-19,82^{\circ}$ ). Esses limites correspondem às bordas N-S do domo alcalino. É importante notar também que os dados apresentam a mesma convergência no regional, principalmente na parte norte do perfil.

Ao comparar o perfil obtido para a filtragem feita pelo método da continuação para cima em relação ao do método do ajuste polinomial robusto, nota-se que este apresenta valores mais elevados nas bordas do perfil, indicando que o perfil desse método apresenta uma influência do campo regional maior do que a observada para o perfil filtrado pelo ajuste polinomial.

0 baixo gravimétrico observado entre os dois maiores picos do perfil gerado pelos três métodos (Fig. 23) está associado à presença do corpo carbonatítico C1 (Fig. 2), intrínseco ao corpo intrusivo alcalino. Considerando que o Complexo Alcalino de Tapira é composto por cerca de 80\% de piroxenito (Araujo et al., 2002), com densidade entre 3,00 e $3,33 \mathrm{~g} / \mathrm{cm}^{3}$, e assumindo a densidade do carbonatito de aproximadamente $2,5 \mathrm{~g} / \mathrm{cm}^{3}$ (Ribeiro \& Mantovani, 2008), é justificado, dessa forma, 0 baixo gravimétrico associado ao mesmo.

Os comportamentos dos perfis traçados sobre os mapas filtrados tanto pelo método da omissão quanto pelo ajuste polinomial robusto (Fig. 23), apresentam uma tendência extremamente parecida relacionada à anomalia, divergindo apenas na amplitude do sinal. 0 perfil referente ao método da continuação para cima, porém, apresentou uma forte atenuação do baixo gravimétrico associado ao carbonatito C1 (Fig. 2). Ao analisar 0 gráfico da Figura 17 nota-se que essa atenuação fica cada vez mais marcante conforme se aumenta a altura considerada para a filtragem.

A comparação entre os perfis das Figuras 19 e 23 permitiu concluir que o método que melhor filtrou a contribuição da componente regional do campo gravimétrico de Tapira, sem atenuar 0 valor esperado para o corpo intrusivo ou para 0 carbonatito, foi 0 ajuste polinomial robusto de grau 1. 


\section{CONCLUSÕES}

Foi realizado um levantamento gravimétrico terrestre sobre a área ocupada pelo complexo e adjacências. A análise dos dados obtidos permitiu estimar o campo gravimétrico regional, para isolar a contribuição gravimétrica do corpo. Para tal, foram analisados quatro métodos de interpolação: inverso da distância, triangulação, kriging e mínima curvatura. A separação da contribuição gravimétrica foi realizada utilizando os métodos da omissão, continuação para cima e ajuste polinomial robusto. Para compará-los, foi traçado um perfil sobre a anomalia gravimétrica isolada em cada caso. A comparação entre diferentes métodos de interpolação, assim como de separação regionalresidual, permitiu determinar qual metodologia melhor se aplica ao alvo do estudo. Verificou-se que o método de interpolação que melhor responde ao caso apresentado é 0 kriging enquanto a separação regional-residual que apresentou melhor resultado foi 0 ajuste polinomial robusto de grau 1.

É provável que, tanto a interpolação feita pelo inverso da distância quanto pela triangulação, apresentassem uma resposta mais satisfatória se tivessem sido aplicadas a uma malha regular com pouco espaçamento entre os dados. Esse procedimento evitaria a formação de bull's-eye e os padrões angulares observados para os pontos mais distantes nos mapas interpolados. Esses métodos possuem ainda a vantagem de gerarem interpolações precisas (Yang et al., 2004) e não apresentarem efeitos de borda nos mapas.

A mínima curvatura apresentou uma interpolação satisfatória para a distribuição de dados considerada, gerando um mapa de anomalia Bouguer com comportamento suave e contínuo como o esperado. Porém esse método gerou um forte efeito de borda, evidenciado principalmente na parte sul do mapa. Esse efeito aparece também no gráfico de ruído da mínima curvatura, sendo a amplitude do resíduo obtida por esse método maior que a observada para a interpolação pelo kriging.

Apesar do bom resultado obtido pela mínima curvatura, 0 método que melhor se adaptou ao comportamento observado para o campo gravitacional na região de Tapira com a distribuição de pontos considerada foi o kriging. Esse método não apresentou efeito de borda nos limites do mapa gerado ou superfícies de tendências, como observado para os demais métodos de interpolação. A distribuição gaussiana dos resíduos obtidos por esse método, assim como pela mínima curvatura, concentra-se principalmente próxima de zero, porém esta atinge valores menores de máximos e mínimos, consolidando esse método como o melhor para o caso em estudo.

A resposta obtida por diferentes métodos de separação regional-residual permitiu identificar o método que melhor isola a contribuição da componente residual, referente à intrusão, da componente regional associada à rocha encaixante.
A separação regional-residual pelo método da omissão é 0 de mais fácil aplicação. Apesar do gráfico do perfil deste método não ter apresentado influência do regional, a anomalia esperada para a intrusão alcalina foi fortemente atenuada. Essa atenuação pode gerar resultados errôneos quando aplicada como processo anterior a uma modelagem. Por isso é recomendada a aplicação dessa metodologia em casos em que a malha de dados considerada seja muito densa, permitindo assim uma melhor eliminação de pontos sobre o objeto de estudo.

A comparação entre os gráficos obtidos pelo ajuste polinomial robusto e pela continuação para cima (Fig. 23) permitiu concluir que o método que melhor isolou as componentes do campo gravitacional foi 0 ajuste polinomial robusto de grau 1.0 gráfico obtido pela continuação para cima evidenciou não apenas que esse método ainda apresentava resíduos do campo regional nas extremidades do gráfico, como atenuou o baixo gravimétrico observado entre os dois maiores picos do perfil, associados à presença do carbonatito $\mathrm{C} 1$ no centro do domo alcalino (Fig. 2).

Considerando que 0 valor da anomalia é de $45 \mathrm{mGal}$, a diferença entre os valores máximos obtidos pelos quatro métodos é relativamente pequena. Isto permite concluir que os ajustes são compatíveis com o esperado, porém ao analisar com mais atenção os resultados notam-se diferenças importantes entre estes. Como por exemplo, a atenuação do valor do baixo gravimétrico observado no perfil do mapa filtrado pelo método da continuação para cima (Fig. 23).

A análise do melhor método de interpolação e de filtragem das componentes regional e residual do campo gravimétrico é uma etapa de extrema importância antes da modelagem dos dados, seja com geometria 2,5D ou 3D. A escolha do método de interpolação ou do filtro aplicado a um determinado conjunto de dados pode alterar 0 comportamento observado para 0 campo, gerando não apenas superfícies de tendência como, até mesmo, intensificar ou atenuar os valores observados. 0 que pode resultar, por sua vez, em um corpo modelado com características diferentes das esperadas ou mesmo observadas em campo. De fato, a modelagem dos dados gravimétricos filtrados pelo método da continuação para cima poderia resultar num modelo 3D com o corpo carbonatítico intrínseco mais superficial do que 0 gerado pelos mesmos dados, porém filtrados pelo ajuste polinomial robusto.

Numa outra oportunidade, os autores apresentarão 0 resultado da modelagem inversa dos dados gravimétricos aqui tratados.

\section{AGRADECIMENTOS}

A realização desse trabalho só foi possível graças aos auxílios financeiros da Fapesp e do CNPq. Agradecemos à Fosfértil que autorizou a entrada em suas dependências onde foram instala- 
das estações gravimétricas em áreas de mineração sob sua concessão; ao professor Wladimir Shukowsky (IAG-USP) pelo apoio na redução dos dados e pelas valiosas discussões e aos técnicos André Rugenski e Eduardo Moraes Leite (ANP) pelo apoio em campo.

\section{REFERÊNCIAS}

ABDELRAHMAN EM, RIAD S, REFAI EM \& AMIN Y. 1985. On the leastsquares residual anomaly determination. Geophysics, 50: 473-480.

ABRAMOWITZ M \& STEGUN IA. 1972. Handbook of mathematical functions. Nova lorque, Dover Publications Co. 885 p.

AGÓCS WB. 1951. Least-squares residual anomaly determination. Geophysics, 16: 686-696.

ARAUJO RVV, SOBRAL LGS \& SANTOS RLC. 2002. Produção de fosfato no Brasil: complexo de mineração de Tapira/Fosfértil. In: ENTMME, XIX, 2002, Recife, Pernambuco. CT 2002-050-00 - Contribuição Técnica ao XIX ENTMME - Recife, Pernambuco (relatório interno). Disponível em: <http://www.cetem.gov.br/publicacao/CTs/CT2002-050-00.pdf>. Acesso em: 15 out. 2008.

BARNES R. 2004. Variogram tutorial. Golden Software Inc. Disponível em: <www.goldensoftware.com/variogramTutorial.pdf>. Acesso em: 06 dez. 2010.

BELTRÃO JF, SILVA JBC \& COSTA JC. 1991. Robust polynomial fitting method for regional gravity estimation. Geophysics, 56(1): 80-89.

BLAKELY RJ. 1996. Potential theory in gravity and magnetic applications. Cambridge Press, $464 \mathrm{p}$

BOHLING G. 2005. Kriging. Kansas Geological Survey. 2005. Disponível em: <http://people.ku.edu/ gbohling/cpe940/Kriging.pdf>. Acesso em: 10 nov. 2008.

BOISSONNAT JD \& GEIGER B. 1992. Three dimensional reconstruction of complex shaper based on the Delaunay triangulation. Rapports de recherche. Programme 4. Robotique, Image et vision. № 1697, p. 4-7, abril de 1992. Disponível em:

$<$ http://hal.inria.fr/docs/00/07/69/34/PDF/RR-1697.pdf>. Acesso em: 18 dez. 2010.

BRACEWELL RN. 1965. The Fourier transform and its applications. McGraw-Hill, Nova lorque, 636 p.

BRIGGS IC. 1974. Machine contouring using minimum curvature. Geophysics, 39: 39-48.

BROD JA. 1999. Petrologia e geoquímica do Complexo de Tapira, Estado de Minas Gerais. Tese (Doutorado em Geologia) - University of Durham, United Kingdom, $486 \mathrm{p}$.

BROD JA, RIBEIRO CC, GASPAR JC, JUNQUEIRA-BROD TC, BARBOSA ESR, RIFFEL BF, SILVA JF, CHABAN N \& FERRARI AJD. 2004. Geologia e mineralizações dos complexos alcalinos-carbonatíticos da província ígnea do Alto Paranaíba. In: Roteiro de excursão do Congresso Brasileiro de Geologia, XLII, 2004, Araxá, Minas Gerais, 29 p.

BROD JA, GASPAR JC, DINIZ-PINTO HS \& JUNQUEIRA-BROD TC. 2005. Spinel chemistry and petrogenetic processes in the Tapira Alkaline-Carbonatite Complex, Minas Gerais, Brasil. Revista Brasileira de Geociências, 35(1): 23-32.

COMIN-CHIARAMONTI P, GOMES CB, CUNDARI A, CASTORINA F \& CENSI P. 2007. A review of carbonatitic magmatism in the ParanáAngola-Namibia (PAN) system. Per. Mineral, 76(2-3): 25-78.

DELAUNAY B. 1934. Sur la sphère vide, Izvestiya Akademii Nauk SSSR, Otdelenie Matematicheskikh i Estestvennykh Nauk, 7:793-800. Disponível em:

$<$ http://en.wikipedia.org/wiki/Delaunay_triangulation\#cite_note-Delaunay1934-0>. Acesso em: 9 nov. 2009

GOL'TSMAN FM. 1977. Problems of the statistical information theory of the interpretation of geophysical observation. Physics of the Solid Earth 13: $873-879$

GUIBAS L \& STOLFI J. 1985. Primitives for the manipulation of general subdivisions and the computation of Voronoi Diagrams. ACM Transactions on Graphics, 4(2): 74-123.

HUBER PJ. 1981. Robust statistic. John Wiley and Sons. 308 p.

LONGMAN IM. 1959. Formulas for computing the tidal accelerations due to the Moon and the Sun. J. Geophys. Res., 64(12): 2351-2355.

MALTA L \& ARAÚJO L. 2009. Triangulação de Delaunay - Geometria Computacional. CPDEE - Universidade Federal de Minas Gerais. Disponível em:

$<$ http://www.cefala.org/ leoca/delaunay/92.html>. Acesso em: 19 out. 2009.

MANTOVANI MSM, RUGENSKI A, DIOGO LA \& SHUKOWSKY W. 2005. Integrated geophysical investigation of a possible new alkaline occurrence in SE Brazil. J. South Amer. Earth Sci., 20: 250-266.

McLINTOCK D, DEREN EJ \& KRAKIWSKY EJ. 1994. Environment sensitive: DGPS and barometry for seismic surveys. GPS Word, 6: 20-26.

MELAMED R, GASPAR JC \& MIEKELEY N. 2007. Pó-de-Rocha como fertilizante alternativo para sistemas de produção sustentáveis em solos tropicais. Série estudos e documentos. SED - 72. Disponível em: $<$ http://www.cetem.gov.br/publicacao/series_sed/sed-72.pdf>. Acesso em: 18 dez. 2010.

NELSI CS. 2001. Apostila de gravimetria. São Paulo: IAG/USP. 90 p.

ON (Observatório Nacional). 2009. Rede Gravimétrica Fundamental Brasileira. Disponível em:

$<$ <htp://www.on.br/conteudo/modelo.php?endereco=servicos/servicos.html> Acesso em: 19 out. 2009. 
RAO BSR, MURPHY IVR \& RAO CV. 1975. A successive approximation method of deriving residual gravity. Geoexpl., 13: 129-135.

RIBEIRO VB \& MANTOVANI MSM. 2008. Gravimetria do Complexo Alcalino de Tapira (MG) - método e interpretação. In: Simpósio de Vulcanismo e Ambientes Associados, 4., 2008, Foz do Iguaçu. Disponível em: <jasper.rc.unesp.br/vulcanismo/trabalhos/ribeiro\%20et\%20al.pdf>. Acesso em: 23 nov. 2010.

RUGENSKI A. 2006. Investigação geofísica dos complexos alcalinos do sul e sudeste do Brasil. 2006. Dissertação (Doutorado em Geofísica) Instituto de Astronomia, Geofísica e Ciências Atmosféricas, Universidade de São Paulo, São Paulo. 352 p.

RUGENSKI A, MANTOVANI MSM \& SHUKOWSKY W. 2001. Modelo gravimétrico do Complexo Alcalino de Pariquera-Açu (SP). Revista Brasileira de Geociências, 31(3): 365-374.

SILVA CH. 2003. Evolução geológica da faixa Brasília na região de Tapira, Sudoeste do estado de Minas Gerais. Tese (Doutorado em Geologia) Universidade Estadual Paulista, Rio Claro - SP, 196 p.

SILVA CH, SIMÕES LSA, KRYMSKY R \& MACAMBIRA MJB. 2006. Proveniência e idade do metamorfismo das rochas da Faixa Brasília, na região de Tapira (SW de Minas Gerais). Geologia - USP, Série Científica, 6(1): 53-66.

SMITH WHF \& WESSEL P. 1990. Gridding with Continuous Curvature Splines in Tension. Geophysics, 55(3): 293-305.

SIMPSON Jr SM. 1954. Least squares polynomial fitting to gravitational data and density plotting by digital computers. Geophysics, 19: 255269.

TAVARES STP, MENDES EC \& RESENDE SE. 2008. Avaliação geometalúrgica da rocha fresca de Tapira, MG. (Relatório interno, 30 pp). Disponível em:

$<$ www.minerios.com.br/PremioExelencia/2008/geologia_fosfertil.pdf>.

Acesso em: 19 out. 2009.

VIGNERESSE JL. 1995. Control of granite emplacement by regional deformation. Tectonophysics, 249(3-4): 173-186.

YANG C, KAO S, LEE F \& HUNG P. 2004. Twelve Different Interpolation methods: A Case Study of Surfer 8.0. Geo-Imagery Bridging Continents, $20^{\text {th }}$ ISPRS Congress, 12-23 July 2004 Istanbul, Turkey. Disponivel em: <http://www.isprs.org/proceedings/XXXV/congress/comm2/papers/231.pdf>. Acesso em: 23 nov. 2010.

\section{NOTAS SOBRE OS AUTORES}

Vanessa Biondo Ribeiro. Formada em Geofísica pelo Instituto de Astronomia, Geofísica e Ciências Atmosféricas da Universidade de São Paulo (IAG/USP). Obteve 0 título de mestre em Geofísica pelo IAG/USP em abril de 2011. Doutoranda em Geofísica pelo IAG/USP com bolsa de estudo do CNPq. Áreas de interesse incluem métodos potenciais aplicados à exploração mineral e vulcanismo continental.

Marta Silvia Maria Mantovani. Bacharel em Física pela Universidade de São Paulo (IF-USP), Doutora em Física pela Universidade Estadual de Campinas (IFUNICAMP), Pós-doutorado na Rice University (EUA), Università degli Studi di Napoli (Itália) e na Universidade de Oxford e na Open University (Inglaterra). É Professora Titular do IAG-USP, Membro da Academia Brasileira de Ciências e da Academia de Ciências do Estado de São Paulo. Áreas de interesse incluem métodos potenciais aplicados à exploração mineral e geoquímica para o estudo de vulcanismo continental. 